\title{
Investment under Uncertainty, Debt, and Taxes
}

\author{
Carmen Aranda León, ${ }^{1}$ \\ Andrea Gamba, ${ }^{2}$ \\ Gordon A. Sick ${ }^{3}$
}

August 4, 2004

${ }^{1}$ University of Navarra, Pamplona, Spain.

${ }^{2}$ SAFE Center, Department of Economics, University of Verona, Verona, Italy

${ }^{3}$ Haskayne School of Business, University of Calgary, Calgary, Canada. 


\begin{abstract}
We present an approach for valuing real investment projects taking into account both personal and corporate taxation, and assuming that the project may also be financed by issuing incremental debt. The setting is a generalized Miller equilibrium economy with differential taxation for bond-holders and equity-holders and with cross-sectional variation in corporate tax rates. We use valuation neutrality (the martingale operator is not affected by taxes) and holding-period neutrality (there are no tax-based incentives to adjust the investment holding period) of the tax scheme. Accordingly, we provide a certainty equivalent (risk-neutral) valuation framework taking into account taxation and valuation of tax shields, for capital budgeting projects both in case the firm can and can prevent default on debt payment.

The certainty-equivalent operator is not affected by tax shields and is the same before and after personal taxes. Interest tax shields can be incorporated by either adjusting the discount rate for interest tax shields (depending on the financincg system) or with an APV-like approach with interest tax shields being additive.

We also analyze also the effect of debt financing on the value of the option to invest and on the exercise policy, including the effect of default risk. One of the findings of this work is that for low uncertainty a higher leverage can reduce the time-value of the real options and increases the probability of exercising these options. This effect is completely offset in case either the uncertainty or the leverage is high; i.e., when the firm is close to default.
\end{abstract}

Keywords: Investment under uncertainty, capital structure, risk-neutral valuation, corporate and personal taxation, default risk.

JEL classifications: G31, G32, C61 


\section{Introduction}

The most widely used models for valuing or optimizing capital investment decisions under uncertainty are based on cash flows discounted at a risk-adjusted rate. Nevertheless, the presence of leverage, discretion and asymmetry forces a valuation approach based on computation of certainty equivalent, as opposed to expected, cash flows. This leads to the real options approach for capital budgeting valuation.

The interaction of personal and corporate taxes on various financing instruments generates a net interest tax shield that may have positive or negative value. This interaction is so often mishandled that few people recognize that it could just as likely have a negative value as a positive value. The differential taxation does not affect the certainty-equivalent (equivalent martingale) operator. The value of the interest tax shield can be calculated either by an additive term that separates the value under different financing scenarios (an adjusted present value or APV treatment), or by adjusting the discount rate to reflect the tax wedge that separates the riskless market returns for instruments of different tax classes in what we will call a tax-adjusted discount rate (TADR) approach.

A equity-finance real investment opportunity (such as an option to pursue an R\&D project) should be discounted at a different riskless discount rate than used for a financial derivative. This is because the marginal investor for a capital investment project is likely to face differential taxation of debt and equity instruments, which drives a tax wedge between the riskless returns on equity and debt instruments. However, the market maker who sets the relative prices of financial derivatives and their underlying instruments is typically taxed at the same rate on all financial instruments, so she does not see a tax wedge between riskless equity and debt instruments. Thus, the common practice of discounting financial derivatives (puts and calls on stocks, for example) at the riskless debt rate is appropriate. However, we show that it is incorrect to carry this practice over to a real options setting, where certainty-equivalents that are financed by equity should be financed by an equity rate that differs (and is typically lower than) the debt rate.

The fact that a financial market maker does not use the same discount rate to value an investment as a long-term capital investor would use does seem to lead to some arbitrage opportunities that we do not explore. It may be difficult to take advantage of these arbitrage opportunities because a dynamic hedge based on the long term capital value may generate adverse tax consequences, or may be had to form because 
of incomplete markets.

Most capital budgeting projects are financed partly by debt and partly by equity. Finally, there are some cash flows from a project, like the tax advantage to debt due to the deduction of interest payments from the taxable income, that are contingent on the cash flow of the project and are lost in case the firm default on debt service. For this case, a suitable valuation approach is needed, based on certainty equivalent operators taking into account personal taxation.

In this work we introduce a continuous-time valuation framework for cash flows emerging in capital budgeting, taking into account personal and corporate taxes, under the assumption that taxes do not introduce tax timing options due to the taxation of capital gains. We do show broad circumstances under which taxes do not affect the equivalent martingale measure.

This paper shows how to adjust the value of discretionary and asymmetric cash flows, in order to apply the real options approach, for the value of debt and taxes under two different types of settings. In the first, we assume that debt is default-free because of the ability of the management to constantly adapt the debt level of the firm. This assumption, first due to Miles and Ezzell (1980, 1985), is widely accepted in capital budgeting (see recently on this Grinblatt and Liu (2002)), and is here considered as the benchmark case. In the second setting, we assume that debt is defaultable and incorporate the effect of the probability of default into the valuation. In this respect, our work extends previous research by Merton (1974), incorporating tax shields; by Brennan and Schwartz (1978), Leland (1994) and Leland and Toft (1996), considering personal and corporate taxation.

Lastly, the paper aims at describing the influence of debt financing on the value of the project and on the decision to invest. The are few other contributions in the real options literature that deal with the interaction between investment and financing decisions.

An early contribution was given by Trigeorgis (1993), who analyzed the option to default on debt payments, noting potential interactions with operating flexibility, but with no reference to tax benefits from debt financing. Another important contribution is Mauer and Triantis (1994), who presented a real options model of a flexible production plant with a capital structure changing over time as a consequence of an optimal dynamic financing policy, but with the important limitation that default is ruled out by the ability to reduce the debt. They do not find any influence of debt financing on the investment policy. In contrast, we show that debt 
financing, also in the default free case, have a deep impact both on the value of the option to invest and on the probability of investing.

A third line of research was started by Mello and Parsons (1992), who studied the effect of agency problems of debt (underinvestment or overinvestment) on the optimal operating policy for the firm with different operating modes and provides a measure of the agency cost of debt. Mauer and Ott (2000) and Childs et al. (2000) extend these results to the case of expansion options. We do not analyze potential conflicts of interest between equity-holders and debt-holders.

Our model is more general than these contributions in that we properly incorporate personal taxation and that we do no assume that debt level is a predetermined function independent of the operating policy (as in Mello and Parsons (1992)) or of the strategic policy (as in Mauer and Ott (2000) and Childs et al. (2000)).

An outline of our work is as follows. First, in Section 2, we provide an equilibrium valuation approach in continuous-time for real and financial assets in an economy with personal and corporate taxes, where tax rates on bonds and stocks are different. In Section 3 we present a continuoustime valuation approach for levered and unlevered real assets for capital budgeting purposes. We study first a case with no default risk, and then we incorporate the possibility that the firm can default on debt payments. In Section 4 we introduce the basic real option to delay an investment under the assumption that the incremental debt to finance the real asset is issued conditional on the decision to invest. In Section 5 we analyze the effect of debt financing on the value of the real option and on the optimal investment policy. The results are sharply different in the default-free case and in the defaultable case. In the first, a higher leverage for a supramarginal firm/project (i.e., a firm/project which has a tax advantage to debt) increases the value of the option to delay investment and increases the probability of investing, thus reducing the time-value of the option to defer investment. In the second case, the positive effect of debt for a supra-marginal firm/project, because of the tax benefit on interest payments, can be completely offset when uncertainty is high and the firm is close to default. 


\section{Asset valuation in a generalized Miller economy}

\subsection{Tax equilibrium}

This section discusses the valuation framework for capital budgeting purposes in a continuous-time Miller economy that is generalized to allow for cross-sectional variation in corporate tax rates. Miller (1977) assumes that the personal tax rate for bond investment income is different from the personal tax rate for stock investment income. He assumes that there is cross-sectional variation in personal tax rates, but not corporate tax rates. Thus, in his tax equilibrium, all corporations are indifferent about capital structure, but individual investors have a tax-induced preference for debt or equity, leading to tax clienteles. By allowing cross-sectional variation in corporate tax rates, as in Sick (1990), only firms at the margin are indifferent (on a tax basis) between issuing debt and equity, and supra-marginal firms with a tax rate below the marginal rate prefer to issue equity and infra-marginal firms with a tax rate above the marginal rate prefer to issue equity.

A cash flow is valued according to an equivalent martingale measure (EMM) that, in principle, may be specific to the form in which the cash flow is conveyed to the investor. We establish circumstances where the tax system is neutral, in the sense that it does not affect the EMM (valuation neutrality). We also establish conditions where the holding-period timing options (as in Constantinides (1983)) have no value (holding-period neutrality). This is crucial when valuing corporate investments, because their cash flow streams must be valued from the point of view of bondholders and equity-holders of the corporation. Although there are several neutral personal tax systems, ${ }^{1}$ we will achieve a neutral tax system with a linear personal taxation scheme (symmetric in gains in losses) that also has a mark-to-market feature that taxes capital gains as accrued rather than when they are realized. ${ }^{2}$ Of course, the relevant personal tax system for any capital budgeting valuation may not be exactly neutral, but it will often be close enough to neutral that the techniques here are the appropriate starting point for valuation and policy decisions.

The setting is an economy with complete financial markets that has both personal and corporate taxes. We assume an underlying complete probability space $(\Omega, \mathcal{F}, \mathbb{P})$ and a (possibly infinite) time horizon $T, \Omega$ is

\footnotetext{
${ }^{1}$ See Auerbach and Bradford (2001).

${ }^{2}$ In Jensen (2003), the proof of valuation neutrality and holding-period neutrality is provided also for other cash flow-based taxation schemes.
} 
the set of possible realizations of the economy, $\mathcal{F}$ is the $\sigma$-field of distinguishable events at $T$, and $\mathbb{P}$ is the actual probability on $\mathcal{F}$. We denote $\mathbb{F}=\left\{\mathcal{F}_{t}, t \in[0, T]\right\}$ the augmented filtration or information generated by the process of security prices, with $\mathcal{F}_{T}=\mathcal{F}$.

We denote by $\tau^{c}$ the marginal tax rate for a company; $\tau^{b}$ the personal tax rate for income from bonds, and $\tau^{e}$ the personal tax rate for income from equities. We assume that, for the individual investor, capital gains and coupons in bond markets are taxed at the same rate, and capital gains and dividends in equity markets are taxed at the same rate. The personal tax operators are linear at any date $t$ (i.e., for each investor, income and losses are taxed, or generate tax relief, at the same rate). On the other hand, the tax scheme for corporations need not be linear. We allow $\tau^{c}, \tau^{b}$ and $\tau^{e}$ to be $\mathbb{F}$-adapted stochastic processes, i.e. they are determined as a function of the (stochastic) factors underlying the economy, but they must have continuous sample paths, almost surely. The stochastic nature of tax rates is not essential to achieve the results of this paper and readers may find it more convenient to think of the tax rates as being deterministic or even constant. In general, $\tau^{b}$ and $\tau^{e}$ are different. Ross (1987) established the existence of equilibrium and of an EMM for an economy with personal taxes and a convex tax schedule. These assumptions are satisfied in our setting.

Consider a firm with tax rate $\tau^{c}$ that is deciding whether to issue debt or equity to an investor who has tax rates $\tau^{e}$ and $\tau^{b}$ on equity and debt respectively. If $\left(1-\tau^{c}\right)\left(1-\tau^{e}\right)>\left(1-\tau^{b}\right)$, the firm has incentives to issue equity. It can even issue equity at a slightly higher after-all-tax rate of return, thereby attracting a new investor with a higher tax rate on equity (relative to debt), who formerly would have purchased debt. (It does this while still paying a lower after-corporate-tax rate of return on the new equity than on the debt.) This switch in marginal investors reduces the gap between $\left(1-\tau^{c}\right)\left(1-\tau^{e}\right)$ and $\left(1-\tau^{b}\right)$. Similarly, if $\left(1-\tau^{c}\right)\left(1-\tau^{e}\right)<\left(1-\tau^{b}\right)$, the firm has incentives to issue debt. This attracts investors who are taxed more heavily on debt.

Equilibrium is achieved by adjusting relative prices on debt and equity, which affects the expected rates of return on these securities. In equilibrium, the marginal firm, with marginal tax rate $\tau^{c}=\tau^{m}$, will be indifferent between issuing debt and equity and the marginal investor (with tax rates $\tau^{e}$ and $\tau^{b}$ ) will be indifferent between buying debt and equity. In this equilibrium, security prices (and expected returns) are such that the after-all-tax returns are the same for the marginal firm and the marginal investor, so that there is no overall gain from debt in this 
economy,

$$
\left(1-\tau^{m}\right)\left(1-\tau^{e}\right)=\left(1-\tau^{b}\right) .
$$

Since there is cross-sectional variation in corporate tax rates $\tau^{c}$, there will be supra- and infra-marginal firms, i.e., firms that have a gain $\left(\tau^{c}>\right.$ $\left.\tau^{m}\right)$ or a loss $\left(\tau^{c}<\tau^{m}\right)$ from leverage, respectively. ${ }^{3}$ We can characterize the marginal firm's tax rate $\tau^{m}$ by the equation

$$
1-\tau^{m}=\frac{1-\tau^{b}}{1-\tau^{e}}
$$

The equilibrium entails setting the expected rates of return on the securities. To set aside risk premia for a moment, we consider riskless debt offering a yield of $r^{f}$ and riskless equity offering a yield of $r^{z}$. In equilibrium, these yields must achieve the same rate of after-all-tax return for the marginal investor investing in the marginal firm:

$$
\left(1-\tau^{e}\right) r^{z}=\left(1-\tau^{b}\right) r^{f} .
$$

Thus, we can characterize (2.1) in terms of market rates of return by:

$$
1-\tau^{m}=\frac{r^{z}}{r^{f}}
$$

Tax arbitrage has a tendency to make all firms behave as if they have the same tax rate. At the corporate level, an arbitrage scheme could involve a highly taxed firm with $\tau^{c}>\tau^{m}$ issuing debt to acquire its own equity, for example. Or, it could involve a low-tax firm issuing equity to buy back debt. We assume that there are tax laws and agency costs ${ }^{4}$ that prevent a firm from undertaking such an arbitrage transaction. Thus, there will generally be supra- and infra-marginal firms in this generalized Miller tax equilibrium.

It is more difficult to generate tax arbitrage opportunities that would have all investors facing the same effective personal tax rate as that held by the marginal investor. This is because personal tax laws identify the individual and generally change when a financial entity (such as a corporation, mutual fund or trust) is inserted between the investor and the investment vehicle. Thus, there will generally be supra- and infra-marginal investors in this generalized Miller tax equilibrium. Indeed, Miller (1977)

\footnotetext{
${ }^{3}$ The fact that some firms have unlevered capital structure can be interpreted as an evidence that there are infra-marginal firms, although an infra-marginal can have leverage because of agency costs in issuing equity.

${ }^{4}$ See for instance, Myers and Majluf (1984).
} 
also assumed this. For example, suppose an investor pays little or no tax on any investment (e.g. a pension fund), but the marginal investor pays higher tax on debt than on equity. The untaxed infra-marginal investor would prefer the tax benefits of debt, but this will prevent the investor from earning risk premia paid on equity investments. We assume that any attempt to convert an equity investment with a risk premium to a debt instrument for tax purposes is prevented by tax law.

Taxes introduce a risk sharing mechanism between government and taxed investors. This could cause a difference between the equilibrium pricing measure with and without personal taxes. We will assume a valuation neutral tax scheme, in the sense that, although individual investors have different tax rates, the market stays in equilibrium since no arbitrage opportunities are introduced and the equilibrium pricing measure is unchanged by the presence of taxation. For valuation purposes, this means that the expected (under the EMM) pre-tax cash flow stream of a security, discounted at a pre-tax rate, is equal to the expected (under the same EMM) after-tax cash flow stream, discounted at an after-tax rate.

A second important issue introduced by taxation of security returns is the presence of timing options related to taxation of capital gains, as pointed out by Constantinides (1983). Taxation of capital gains produces timing options due to a (rational) delay of liquidation of positions in financial securities, until a date of forced liquidation, if the accrued capital gain is positive and the anticipation of liquidation of the position if the capital gain is negative, to take advantage of the tax credit.

We assume a holding-period neutral tax scheme, ${ }^{5}$ i.e. a tax scheme that does not introduce any timing options related to taxation of capital gains and so it does not change portfolio strategies of individual investors. Auerbach (1991) and Auerbach and Bradford (2001) describe a generalized tax scheme that prevent tax arbitrages and realizes holding-period neutrality. ${ }^{6}$ Within this class of valuation and holding-period neutral tax schemes, we will consider the mark-to-market personal taxation. Mark-

\footnotetext{
${ }^{5}$ To the best of our knowledge, the definition of holding-period neutrality is due to Auerbach (1991, p. 169):

"A realization-based tax system is holding-period neutral if it leads each investor in an asset to require a before-tax return having a certaintyequivalent value that is not a function of the length of holding period or the asset's past pattern of return."

${ }^{6}$ Jensen (2003) provides an exhaustive characterization of the class of taxation schemes that satisfy the requirements of valuation and holding-period neutrality in a discrete-time setting.
} 
to-market taxation of a security consists of accrual of taxes on capital gains on a separate account as if the security were actually traded. The realization of the accrued tax on capital gain is deferred until the date the security is actually traded. There are several practical problems related to this scheme, especially when related to illiquid (or inefficiently traded) securities. As far as a no-arbitrage financial market is concerned, the main drawback of mark-to-market taxation is related to the liquidity constraints it imposes on the individual investors. Nevertheless, markto-market taxation is a reasonable benchmark and has been used for this in the public finance literature. ${ }^{7}$

\subsection{Security price dynamics}

In the economy described above, ${ }^{8}$ let $\mathbb{Q}$ be an EMM on $\mathcal{F} .{ }^{9}$ We denote the risk-neutral expectation operator with respect to $\mathbb{Q}$ as $\mathbb{E}^{\mathbb{Q}}\left[\cdot \mid \mathcal{F}_{t}\right]=\hat{\mathbb{E}}_{t}[\cdot]$.

The price of an arbitrary stock, denoted $S$, is an adapted Itô process $\left\{S_{t}\right\}$ with dynamic (under $\mathbb{Q}$ )

$$
d S_{t}=\left(r_{t}^{z} S_{t}-X_{t}\right) d t+\sigma_{t} d Z_{t} \quad S(0)=S_{0} .
$$

$\left(r^{z}, X_{t}\right.$ and $\sigma_{t}$ are adapted processes which satisfy the usual integrability conditions) where $r_{t}^{z}$ is the time- $t$ certainty equivalent (CE) instantaneous rate of return for a stock at the market level (before-personal taxes) under the EMM, and where the adapted process $X_{t}$ is the flow of dividends. We make the assumption that taxes on dividends are levied at the same rate as taxes on capital gains as far as the same investor is concerned.

We define also a money market account, ${ }^{10}$ at the market level, of value

\footnotetext{
${ }^{7}$ An extension of the results presented below to other neutral taxation scheme is beyond the scope of this paper and will be the subject of future research. We will provide our results in a continuous-time Miller (1977) setting, where the tax rate for bonds and the tax rate for stocks can be different even if they are traded by the same agent. Our results significantly extend Jensen (2003) results to an economy where personal tax rates can be cross-sectionally different and bonds are taxed differently from bonds.

${ }^{8}$ We skip the description of the other technical hypotheses suited for the existence of an EMM for valuing the securities. Interested readers can refer to Duffie (2001).

${ }^{9}$ Since in principle the EMM can be affected by personal taxation, our choice of $\mathbb{Q}$ is arbitrary for the time being. As we will prove later, under the mark-to-market symmetric tax scheme the EMM is not affected by taxation. Hence, $\mathbb{Q}$ will be legitimately defined as the equilibrium EMM.

${ }^{10}$ Here we will concentrate on default-free bonds. We postpone the valuation of defaultable bonds, like corporate bonds, until Section 3.3, where we introduce endogenous default and the valuation formula will be more easily introduced.
} 
$B$ with dynamics (before personal tax):

$$
d B_{t}=r_{t}^{f} B_{t} d t \quad B_{0}=1
$$

where the riskless rate of return or CE rate, $r_{t}^{f}$, is an adapted process (and satisfies the standard conditions). thus

$$
B_{t}=\exp \left(\int_{0}^{t} r_{u}^{f} d u\right)
$$

The equilibrium rates of return on the money market and stock market are the same after all taxes for the marginal investor, so, at any date $t$ we have (generalized Miller equilibrium relation) that yields a common after-all-tax riskless CE return $r_{t}^{z \text {,at }}$

$$
r_{t}^{z, \text { at }} \equiv r_{t}^{f}\left(1-\tau_{t}^{b}\right)=r_{t}^{z}\left(1-\tau_{t}^{e}\right)
$$

or $^{11}$

$$
r^{z}=\left(1-\tau^{m}\right) r^{f}
$$

Generally $r^{z} \leq r^{f}$, since the marginal firm's tax rate $\tau^{m} \geq 0$. This requires that the marginal investor's debt tax rate exceeds her equity tax rate: $\tau^{b} \geq \tau^{e}$. Only if $\tau^{b}=\tau^{e}$ (or equivalently, $\tau_{m}=0$ ) can we have $r^{z}=r^{f}{ }^{12}$ In what follows, we only require that all tax rates be between 0 and 1: $0 \leq \tau^{b}, \tau^{b} \tau^{c}, \tau^{m}<1$. Thus, taxation is never confiscatory. For convenience, we define

$$
B_{t}^{z}=\exp \left(\int_{0}^{t} r_{u}^{z} d u\right)
$$

to be the accumulated value of an investment in the CE equity account.

\footnotetext{
${ }^{11}$ Equation (2.6) provides also a way to estimate the marginal tax rate $\tau^{m}$, since $r^{z}$ and $r^{f}$ can either be observed or derived from security prices.

${ }^{12}$ The assumption that $\tau^{b}=\tau^{e}$ is very common in the literature. For example, it was used by Modigliani and Miller (1963) and underlies most of the standard exposition of the CAPM, such as Sharpe (1964) and APT as in Ross (1976). The more accurate assumption, as in Miller (1977) and others is differential taxation of debt and equity income, typically $\tau^{b} \geq \tau^{e}$. This forces us to deal with differential riskless rates in debt and equity markets. Typically $r^{f} \geq r^{z}$, although our results do not depend on this condition.
} 


\subsection{Valuation neutrality and holding-period neutrality}

Using the martingale valuation results, ${ }^{13}$ given a maturity date $T^{\prime}>t$ (where $T^{\prime}$ is a stopping time with respect to $\mathbb{F}$ ) the market price of the stock at time $t$ (i.e., before personal taxes) is

$$
S_{t}=B_{t}^{z} \hat{\mathbb{E}}_{t}\left[\frac{S_{T^{\prime}}}{B_{T^{\prime}}^{z}}+\int_{t}^{T^{\prime}} \frac{X_{u}}{B_{u}^{z}} d u\right]
$$

which is the value of the stock at the market level (i.e., before personal taxes), given by the CE price at $T^{\prime}$ discounted at the CE equity rate. Let

$$
B_{t}^{z, \text { at }} \equiv \exp \left(\int_{0}^{t} r_{u}^{z}\left(1-\tau_{u}^{e}\right) d u\right)
$$

be the time- $t$ value of one dollar invested at time 0 and earning the CE rate of return on equity $r_{u}^{z}$ net of personal taxes $\tau_{u}^{e}$ for $0 \leq u \leq t$.

Define the after-all-tax stock value $S_{t}^{\text {at }}$ by

$$
S_{t}^{\mathrm{at}}=B_{t}^{z, \mathrm{at}} \hat{\mathbb{E}}_{t}\left[\frac{S_{T^{\prime}}}{B_{T^{\prime}}^{z, \mathrm{at}}}+\int_{t}^{T^{\prime}} \frac{\left(1-\boldsymbol{\tau}_{u}^{e}\right) X_{u}}{B_{u}^{z, \mathrm{at}}} d u-\int_{t}^{T^{\prime}} \frac{\boldsymbol{\tau}_{u}^{e}}{B_{u}^{z, \mathrm{at}}} d S_{u}^{\mathrm{at}}\right] .
$$

This is the value of the stock after personal taxes and is defined as the certainty-equivalent after-personal-tax price at $T^{\prime}$, and all after tax dievidends, discounted at the after-tax CE equity rate. This is a recursive definition, initially defining $S_{t}^{\text {at }}=S_{T^{\prime}}$ for $t=T^{\prime}$ and working backwards for earlier $t$. Note that the definition uses the same risk-neutral expectations $\hat{\mathbb{E}}_{t}[\cdot]$ and probability measure $\mathbb{Q}$ as is used for the pretax value $S_{t}$. We will show that this is the same as the pre-personal-tax value of the stock.

Equation (2.8) implements a mark-to-market taxation rule. That is, each period, capital gains (or losses, if negative) are taxed as accrued

\footnotetext{
${ }^{13}$ Ross (1987) shows that there is an equivalent martingale pricing operator in the presence of taxes. His results are general and, in our setting, establish a pricing operator after all taxes, as well as pricing operators for debt flows before personal tax and for equity flows before personal tax. Even if each of these three pricing operators is unique within its own setting, there is no immediate guarantee that these pricing operators are related or equivalent. Sick (1990) raised this question in a discrete-time setting and showed that the certainty equivalent operators associated with these pricing operators are all identical to each other. That is, taxes and tax shields do not generate a risk premium. We establish an equivalent result in continuous time, but initially, we must be careful to distinguish the source of any pricing operator. For the time being, we take the martingale pricing operator that prices equity cash flows after corporate tax and before personal tax.
} 
even though they are not realized. This tax scheme requires that, at the date of liquidation, the capital gains in the interval $\left[t, T^{\prime}\right]$ are considered at the date they occur and then interest accrues on the tax on capital gains at the after-personal tax rate of return until $T^{\prime}$. The tax on capital gains (on the after-tax stock price $S_{t}^{\text {at }}$ ) accrued from $t$ to $T^{\prime}$ and paid at the liquidation date $T^{\prime}$ is $B_{t}^{z \text {,at }} \int_{t}^{T^{\prime}} \tau_{u}^{e} / B_{u}^{z \text {,at }} d S_{u}^{\text {at }}$. This amount is specific to the realized path for $S_{t}^{\text {at }}$. In Equation (2.8), the present value at $t$ of the tax on capital gains realized at time $u \geq t$ is computed by discounting by the factor $B_{t}^{z, a t} / B_{u}^{z, \text { at }}$. The expectation of this discounted value is taken with respect to the (risk-neutral) probability of all future paths for $S_{t}^{\text {at }}$.

For the money market account, we denote the value of a unit-dollar amount accrued at the after-personal-tax rate $r_{t}^{f}\left(1-\tau_{t}^{b}\right)$ by

$$
B_{t}^{f, \text { at }}=\exp \left(\int_{0}^{t} r_{u}^{f}\left(1-\tau_{u}^{b}\right) d u\right) .
$$

Since the equilibrium relation in (2.5) holds at any $t$, we have $B^{f \text {, at }}=$ $B^{z, \text { at }} \forall t$. Analogous to definition (2.8) for stocks, we define the after-alltax bond value $B_{t}^{\text {at }}$ by

$$
B_{t}^{\mathrm{at}}=B_{t}^{f, \text { at }} \hat{\mathbb{E}}_{t}\left[\frac{B_{T^{\prime}}}{B_{T^{\prime}}^{f, \mathrm{at}}}-\int_{t}^{T^{\prime}} \frac{\tau_{u}^{b}}{B_{u}^{f, \mathrm{at}}} d B_{u}^{\mathrm{at}}\right] .
$$

Proposition 1. Under the linear mark-to-market taxation rule:

1. the value of the stock at the market level equals the value of the stock after personal taxes: $S_{t}=S_{t}^{\text {at }}$, and

2. the value of the money market account before personal taxes is equal to the value of the money market account after personal taxes: $B_{t}=$ $B_{t}^{\text {at }}$.

This result is often described as a system of taxation that is value neutral. In fact, the next result is an extension of Sick (1990, Proposition 1) to a continuous-time setting.

Corollary 2. The martingale expectation operator $\hat{\mathbb{E}}$, or equivalently, the risk-neutral measure $\mathbb{Q}$ correctly values both equity (and money market) payoffs that are after personal taxes as well as equity (and money market) payoffs that are before personal taxes. 
We have implicitly assumed that the personal equity tax rate $\tau_{t}^{e}$ is the tax rate of the marginal investor, because we have been developing relationships for equilibrium prices. However, the same result holds true for any investor, whether or not he is marginal, provided that the tax schedule is locally linear. That is to say that the marginal payoffs provided by the investment under consideration will cause variation along a portion of the tax schedule that has a constant marginal tax rate.

Corollary 3. If an investor has a tax schedule that is locally linear in equity (bond) income at rate $\tau_{t}^{e}\left(\tau_{t}^{b}\right)$, then the personal valuation of the riskneutral expectation of a pretax stream of equity (money market account) flows discounted at the CE discount rate for equity $r_{t}^{z}\left(a t r_{t}^{f}\right)$ has the same value as a stream of equity (money market account) values net of mark-tomarket capital gains tax, if discounted at the investor's personal after-tax equity (bond) rate $r_{t}^{z, \text { at }}\left(r_{t}^{f, \text { at }}\right)$.

It should be clear now also that the choice of a given EMM, $\mathbb{Q}$, was just for the sake of definiteness, since the argument could be applied for any EMM. Hence, under a mark-to-market linear personal tax system, the EMM is not affected by taxes.

We have discussed the valuation neutrality property of a linear markto-market taxation scheme. We will also show that such a scheme is holding-period neutral, in the sense that it does not change the set of opportunities available to the investor by inducing timing options.

Proposition 4. Under the linear mark-to-market taxation rule and in equilibrium, for the marginal investor no further incentives for liquidating a position are introduced by taxation; i.e., tax options are worthless.

We remark that the assumption of Miller equilibrium (i.e., condition (2.5)) is crucial for this result, since this permits us to "transfer" the tax account back and forth over time at the unique after-personal taxes rate of return $r^{f}\left(1-\tau^{b}\right)=r^{z}\left(1-\tau^{e}\right)$ for the marginal investor.

The above results, and in particular the valuation equations at the market level (i.e., after corporate taxes and before personal taxes) for bonds and stocks, will be useful to evaluate general cash flows to equityholders and debt-holders (at the market level) generated by capital budgeting projects. In this sense, Propositions 1 and 4 make sure that the value of these general cash flows are the same even if we introduce a symmetric mark-to-market taxation (although at cross-sectionally different rates) for bond-holders and debt-holders. 


\section{Capital budgeting with exogenous capital structure in a generalized Miller economy}

In the framework described in Section 2, we introduce capital budgeting valuation, assuming that the corporation has an exogenously given capital structure. The capital structure can be the one proposed by Modigliani and Miller (1958), with constant level of debt, or the one proposed by Miles and Ezzell (1985), with constant debt proportion, or a more general class proposed by Grinblatt and Liu (2002). ${ }^{14}$ We will examine both the default-free case (constant debt proportion or Miles and Ezzell (1980) debt policy) and the case with defaultable debt (constant debt level or Modigliani and Miller (1958) debt policy), assuming that the default threshold is predetermined.

For capital budgeting valuation, since the interest payments on debt are tax deductible, it is important to evaluate the interest tax shield to determine the cost of capital. The tax shield is a function of the leverage of the firm/project and is contingent on the cash flow process, since it is lost in case of financial distress. ${ }^{15}$ Hence, a proper valuation of tax shield can be done only in a risk-neutral setting. ${ }^{16}$ Moreover, the interest tax shield can be positive (for a supra-marginal firm, $\tau^{c}>\tau^{m}$ ) or negative (for an infra-marginal firm, $\tau^{c}<\tau^{m}$ ) as a consequence of the level of the equilibrium marginal tax rate, $\tau^{m} .17$ This makes the framework described in Section 2 appropriate for capital budgeting valuation.

\footnotetext{
${ }^{14}$ We will not consider model with endogenous capital structure, as Fisher et al. (1989), Mauer and Triantis (1994), Goldstein et al. (2001), Dangl and Zechner (2003), Christensen et al. (2002). Capital budgeting valuation with endogenous financial decisions will be the subject for future research.

${ }^{15}$ This is witnessed also by Leland (1994, p. 1220): under the U.S. tax code, the tax benefit on coupon payment is allowed only if EBIT is grater than coupon.

${ }^{16}$ Of course, there can be other contingent claims in capital budgeting, like real options. The extension of the results of this section to real options are in Section 4.

${ }^{17}$ Although we will focus on the supra-marginal case, our results holds true also for the infra-marginal case.
} 


\subsection{Valuation of tax shields}

Let there be given a firm/project, ${ }^{18}$ with marginal corporate tax rate $\tau^{c}$. We assume that $\tau^{c}$ is independent of earnings.

The firm/project has duration $T^{p}$ (possibly, infinite) and the EBIT (Earning Before Interest and Taxes, i.e. a before-corporate taxes free cash flow) rate, $X_{t}$. The EBIT rate follows the adapted process, under the EMM

$$
d X_{s}=g\left(X_{s}, s\right) d s+\sigma\left(X_{s}, s\right) d Z_{s}, \quad X_{t}=x,
$$

where $g$ is the instantaneous CE growth rate and $\sigma$ is the diffusion.

For convenience, we derive first the value of the firm/project assuming it is unlevered. The after-personal tax total cash flow from the firm/project is $X_{t}\left(1-\tau_{t}^{c}\right)\left(1-\tau_{t}^{e}\right)$. Since in Propositions 1 and 4 we established the equivalence of a before- and after- personal taxes valuation for equity income, assuming that the after corporate tax earning are immediately paid to equity-holders, the value of the unlevered firm/project, denoted $U$, by straightforward applications of the pricing relations is Section 2 , is

$$
U(t, x)=B_{t}^{z} \hat{\mathbb{E}}_{t}\left[\int_{t}^{T^{p}} \frac{X_{S}\left(1-\tau_{s}^{c}\right)}{B_{S}^{z}} d s\right]
$$

for $0 \leq t \leq T^{p}$.

In what follows we determine the Adjusted Present Value (APV), i.e. the value of the firm/project including the value of the tax advantage to debt, in case operations are financed also with debt: we will analyze first the default-free case and than we will consider the case with defaultable debt.

\subsection{Default-free debt}

In this section we will assume also that there is no default, because of the ability of the management to constantly adapt, at zero adjustment costs, the debt level in order to avoid default. This implies that the coupon rate for corporate bonds is the risk free rate.

Since the firm/project is financed also by issuing coupon bonds, assuming interest on debt is paid out immediately, given the total coupon

\footnotetext{
${ }^{18}$ Note that, for the time being, and in the sake of simplicity, our setting is different from the case of an ongoing company with its own capital structure and growth options. We will show that the cost of capital for the option to delay investment in the project is independent of the current capital structure of the company, so our choice is legitimate.
} 
rate paid to bond-holders $R_{t}$, then the (instantaneous) cash flow to equityholders is $\left(X_{t}-R_{t}\right)\left(1-\tau_{t}^{c}\right)\left(1-\tau_{t}^{e}\right)$ and to debt-holders is $R_{t}\left(1-\tau_{t}^{b}\right)$, so that the total cash flow from the project is, after-personal taxes,

$$
\begin{aligned}
\left(X_{t}-R_{t}\right)\left(1-\tau_{t}^{c}\right)\left(1-\tau_{t}^{e}\right) & +R_{t}\left(1-\tau_{t}^{b}\right) \\
& =X_{t}\left(1-\tau_{t}^{c}\right)\left(1-\tau_{t}^{e}\right)+\tau_{t}^{*} R_{t}\left(1-\tau_{t}^{e}\right),
\end{aligned}
$$

for $0 \leq t \leq T^{d}$, where $\tau^{*}=\tau^{c}-\tau^{m}$ and $\tau^{m}$ is the marginal tax rate defined in (2.1). We assume that the principal is paid back at $T^{d} \leq T^{p}$. Alternatively, if we are valuing an infinite-horizon project we will assume that it is financed by issuing consol bonds $\left(T^{d}=\infty\right)$. Moreover, for simplicity we assume that debt is always valued at par. Since debt is defaultfree, $R_{t}=r_{t}^{f} D(t, x)$, where $D(t, x)$ is the market value of debt. Hence, $R_{t}$ is an adapted process.

In equation (3.3), while $X_{t}\left(1-\tau_{t}^{c}\right)\left(1-\tau_{t}^{e}\right)$ coincides with the after personal taxes flow for an all-equity financed project, the (net) tax shield, $\tau_{t}^{*} R_{t}$, is taxed at the equity rate because it accrues to equity-holders. ${ }^{19}$ Hence, the right-hand-side of (3.3) must be discounted using the afterpersonal taxes discount factor for stocks, $B^{z \text {,at }}$. From Propositions 1 and 4 , we know that this is equivalent to a before-personal taxes valuation using the discount factor $B^{z}$. This intuition is made precise in the subsequent proposition. We denote $V$ the APV of the levered firm/project. Hence, the levered project (and in particular, the tax shield) is a contingent claim of the free cash flow.

Proposition 5. The APV, incorporating the value of the tax shield, satisfies equation

$$
\frac{1}{2} \sigma^{2}(X, t) \frac{\partial^{2} V}{\partial X^{2}}+g(X, t) \frac{\partial V}{\partial X}+\frac{\partial V}{\partial t}+X_{t}\left(1-\tau_{t}^{c}\right)+\tau_{t}^{*} R_{t}=r_{t}^{z} V
$$

\footnotetext{
${ }^{19}$ Sick (1990) was the first to point out this fact. A possible interpretation of (3.3) is the following: a bond can be interpreted as a swap between equity-holders and the marginal investor, who is indifferent between receiving cash flow from equities and cash flows from bonds. At $t=0$, equity-holders swap $B$ dollars of equity for an equivalent amount (at the market value) of debt, so, the initial net position for equityholders is equal to 0 . At every coupon date, they save to pay a required rate of return $r^{z} B$ and pay $r^{f}\left(1-\tau^{c}\right) B$ to debt-holders, so the net position for equity-holders is $r^{z} B-r^{f}\left(1-\tau^{c}\right) B$. Since the generalized Miller equilibrium relation (2.6) holds for the marginal investor, the net position for equity-holders is $r^{f} B\left(\tau^{c}-\tau^{m}\right)$, where $r^{f} B$ is the CE coupon (which coincides with the actual coupon at the current date), derived from the valuation equation for debt.
} 
with boundary conditions $V\left(T^{d}, X_{T^{d}}\right)=U\left(T^{d}, X_{T^{d}}\right)$ and $U\left(T^{p}, X_{T^{p}}\right)=0$, and is

$$
\begin{gathered}
V(t, x)=B_{t}^{z} \hat{\mathbb{E}}_{t}\left[\int_{t}^{T^{d}} \frac{X_{S}\left(1-\tau_{s}^{c}\right)+T_{s}^{*} R_{s}}{B_{S}^{z}} d s+\frac{U\left(T^{d}, X_{T^{d}}\right)}{B_{T^{d}}^{z}}\right] \\
=U(t, x)+B_{t}^{z} \hat{\mathbb{E}}_{t}\left[\int_{t}^{T^{d}} \frac{\tau_{s}^{*} R_{s}}{B_{s}^{z}} d s\right],
\end{gathered}
$$

for $0 \leq t \leq T^{d}$, where the second term in the right-hand-side is the tax shield.

The APV in (3.5) can be computed in the general case, for general processes for $X_{t}$ and $R_{t}$, for the risk-free rate and for the tax rates, using some numerical methods. ${ }^{20}$ Nevertheless, to obtain a default-free debt, we have to properly define the debt policy: in particular, we assume that $D(t, x)$ is a linear function of $A P V: D=L V$, where $L$ is the constant debt ratio, $0 \leq L<1$. This is the Miles and Ezzell $(1980,1985)$ (M-E) debt policy. 21

By replacing this condition in equation (3.4) we obtain

$$
\frac{1}{2} \sigma^{2}(X, t) \frac{\partial^{2} V}{\partial X^{2}}+g(X, t) \frac{\partial V}{\partial X}+\frac{\partial V}{\partial t}+X_{t}\left(1-\tau_{t}^{c}\right)=\rho_{t} V
$$

where

$$
\rho_{t}=r_{t}^{z}-\tau^{*} r_{t}^{f} L=(1-L) r_{t}^{z}+L\left(1-\tau_{t}^{c}\right) r_{t}^{f}
$$

is the tax-adjusted certainty equivalent cost of capital, i.e., the cost of capital under the EMM that incorporates also the effect of tax shield. From the right-hand-side of equation (3.7) we notice that $\rho_{t}$ is also a weighted average cost of capital (wacc) under the EMM. This is an extension of the tax-adjusted rate of return in Sick (1990) to a continuous-time setting.

Applying conditions $V\left(T^{d}, X_{T^{d}}\right)=U\left(T^{d}, X_{T^{d}}\right)$ and $U\left(T^{p}, X_{T^{p}}\right)=0$, and considering that, for $t>T^{d}, D \equiv 0$ (since $R \equiv 0$ ), ${ }^{22}$ we have that the APV of the firm/project is

$$
V(t, x)=B_{t}^{w} \hat{\mathbb{E}}_{t}\left[\int_{t}^{T^{d}} \frac{X_{s}\left(1-\tau_{s}^{c}\right)}{B_{s}^{w}} d s\right]+B_{t}^{z} \hat{\mathbb{E}}_{t}\left[\frac{U\left(T^{d}, X_{T^{d}}\right)}{B_{T^{d}}^{z}}\right],
$$

\footnotetext{
${ }^{20}$ Monte Carlo simulation is particularly suited for solving this types of problems.

${ }^{21}$ We will prove below that M-E debt policy is actually consistent with the assumption of absence of default.

${ }^{22}$ The argument is the same used in the proof of Proposition 5.
} 
for $0 \leq t \leq T^{d}$, where $B_{t}^{w}=\exp \int_{0}^{t} \rho_{u} d u$ is the time- $t$ value of one dollar accrued at the tax-adjusted CE cost of capital. Equation (3.8) when compared to (3.2) clarifies the role of the tax-adjusted CE cost of capital, $\rho_{t}$, as the stochastic instantaneous discount rate that generates the levered asset value when applied to the unlevered cash flow process. ${ }^{23}$ In particular, the randomness of $\rho_{t}$ derives from the randomness of $r_{t}^{z}$ and $r_{t}^{f}$, but not from the leverage ratio. Hence, equation (3.8) provides a time-consistent pricing operator for levered cash flows.

Equation (3.8) can be use, employing some numerical methods, to compute the APV of the firm/project using a stochastic wacc under general hypotheses on the relevant stochastic processes.

For convenience of analysis, in what remains of this part we derive some closed-form formulas for the tax shield under more restrictive assumptions on the stochastic process for $X$ and the model parameters. In details: the corporate $\left(\tau^{c}\right)$ and the personal $\left(\tau^{e}\right.$ and $\left.\tau^{b}\right)$ tax rates are constant; the CE rates for bonds $\left(r^{f}\right)$ and equities $\left(r^{z}\right)$ are constant; ${ }^{24}$ for the EBIT process in (3.1), the growth rate, $g(X, t)=g X$, and the volatility, $\sigma(X, t)=\sigma X$, where $g$ and $\sigma$ are given constant.

Under these hypotheses, the value of the unlevered firm/project in (3.2) becomes

$$
U(t, x)=x\left(1-\tau^{c}\right) \frac{1-e^{-\left(r^{z}-g\right)\left(T^{p}-t\right)}}{r^{z}-g} .
$$

In order to derive the APV of the firm/project, we observe that the solution is of the type

$$
V(t, x)=U(t, x)+k(t) x
$$

(where $k$ is a function of time to be determined) and hence debt tax shield at $t$ is related to the current value of $X_{t}$. By replacing (3.10) in (3.4) (and

\footnotetext{
${ }^{23}$ Grinblatt and Liu (2002) have an analogue definition of wacc, although they limit the analysis to a less general setting with constant rate of returns and with $\tau^{m} \equiv 0$.

${ }^{24}$ This hypothesis implies in particular that the yield curve for bonds is flat and hence maturity for corporate bonds is irrelevant.
} 
considering that $D=L V$ ) we have $\mathrm{e}^{25}$

$$
\begin{aligned}
& k(t)=\left(1-\tau^{c}\right) r^{f} T^{*} L \frac{\left(1-e^{-\left(r^{z}-g\right)\left(T^{d}-t\right)}\right)}{\left(r^{z}-g\right)\left(r^{z}-r^{f} T^{*} L-g\right)}+ \\
&+\left(1-\tau^{c}\right) e^{-\left(r^{z}-g\right)\left(T^{d}-t\right)} \frac{\left(1-e^{\left(r^{f} T^{*} L\right)\left(T^{d}-t\right)}\right)}{\left(r^{z}-r^{f} T^{*} L-g\right)}
\end{aligned}
$$

for $0 \leq t \leq T^{d}$. We remark that for a marginal firm/project $\tau^{c}=\tau^{m}$ (or $\tau^{*}=0$ ), and hence $k \equiv 0$. Replacing $k(t)$ from (3.11) in (3.10) and after few manipulations we obtain

$$
\begin{aligned}
V(t, x)=x\left(1-\tau^{c}\right) & \frac{1-e^{(\rho-g)\left(T^{d}-t\right)}}{\rho-g} \\
& +e^{-\left(r^{z}-g\right)\left(T^{d}-t\right)} x\left(1-\tau^{c}\right) \frac{1-e^{-\left(r^{z}-g\right)\left(T^{p}-T^{d}\right)}}{r^{z}-g}
\end{aligned}
$$

with $\rho=\rho_{t}$ for all $t$ from equation (3.7), which is the analogue of equation (3.8) under the current more restrictive assumptions.

Equation (3.12) and condition $D=L V$ permit us to prove that the M-E debt policy is consistent with the assumption of absence of default, since $R_{t}$ is a linear function of $X_{t}: R_{t}=\gamma(t) X_{t}$, where $\gamma(t)$ is determined by the results stated above. Hence, in case $X \rightarrow 0$, also $R \rightarrow 0$, and the debt is default-free.

In capital budgeting it is customary to use the (current) wacc to discount expected free cash flows in order to obtain the levered asset value. Under the current more restrictive hypotheses, wacc from equation (3.7) is non-stochastic and hence it can be used for valuation purposes as long as the firm/project is financed also with debt. ${ }^{26}$

\footnotetext{
${ }^{25}$ To obtain equation (3.11) we note that $U$ from equation (3.2) satisfies the pde

$$
\frac{1}{2} \sigma^{2}(X, t) \frac{\partial^{2} U}{\partial X^{2}}+g(X, t) \frac{\partial U}{\partial X}+\frac{\partial U}{\partial t}+X_{t}\left(1-\tau^{c}\right)=r_{t}^{z} U
$$

Moreover, we consider the terminal condition $k\left(T^{d}\right)=0$.

${ }^{26}$ This is in contrast with the conclusions of Grinblatt and Liu (2002), who show that the circumstances for a non-stochastic wacc are, besides the fact that debt is default-free, $X$ following a geometric Brownian motion with constant parameters and constant risk-free rate, that the firm/project is perpetual. Here we have just proved that the constant (initial) wacc can be used, under the M-E scheme, also if debt has finite maturity.
} 
If the firm/project (and debt) is infinite-lived, $T^{d}=T^{p}=\infty$, assuming that the conditions for convergence, $r^{z}-r^{f} T^{*} L>g$ and $r^{z}>g,{ }^{27}$ hold true, then from equation (3.12) (note that $D=L V$ and $R_{t}=r^{f} D(x)$ )

$$
V(x)=U(x)+\frac{\tau^{*} R_{t}}{r^{z}-g},
$$

with $U(x)=x\left(1-\tau^{c}\right) /\left(r^{z}-g\right)$. Equation (3.13) is the analogue of equation (3.5) when debt is default-free, using the M-E constant leverage ratio and the EBIT process is a geometric Brownian motion with constant parameters.

\subsection{Defaultable debt}

If default can be prevented, the effect of debt for a supra-marginal firm is always positive, and only the equilibrium of the financial market (and potential agency costs and tax laws) prevents the realization of a tax arbitrage, as in Miller (1977). On the other hand, if default can actually happen, then the cost of debt is influenced by the credit risk and this tends to reduce the tax advantage to debt. We will show that this affects also the investment policy.

We will limit the analysis to the case of exogenous default; i.e., we assume that there is a given barrier, denoted $x_{D}$, such that, when the EBIT process $X_{t}$ breaches the barrier, the firm is in default. ${ }^{28}$ In this case, the bond-holders file for bankruptcy and receive the value of the unlevered asset net of bankruptcy costs. Bankruptcy costs are assumed to be proportional to the unlevered asset value, with known proportion $\alpha$.

As long as the EBIT process $X_{t}$ is above the default threshold $x_{D}$, the total cash flow generated by the firm is, after personal taxes, as in equation (3.3). On the other hand, if at date $t, X_{t}=x_{D}$, the firm defaults on the coupon payment and so the tax shield is lost. In this case, the value of the levered asset is used to pay bond-holders, who receive (1 $\alpha) U\left(t, x_{D}\right)$. When bond-holders file for bankruptcy, they become owners of the firm. Hence they receive the present value of EBIT after corporate taxes and after personal taxes for equity flows. From Proposition 1 and 4 , the valuation on an after personal tax basis is equivalent to a beforepersonal taxes valuation using the discount factor $B^{z}$. This is stated in the following proposition.

\footnotetext{
27 Note that, for a supra-marginal firm, $r^{z}-r^{f} T^{*} L>g$ implies $r^{z}>g$.

${ }^{28}$ See Leland (1994) for a discussion on what a plausible level for $x_{D}$ should be.
} 
Proposition 6. The APV, incorporating the value of tax shield, satisfies equation (3.4) with boundary conditions $V\left(T^{d}, x\right)=U\left(T^{d}, x\right)$ and $U\left(T^{p}, x\right)=$ 0 and $V\left(s, x_{D}\right)=(1-\alpha) U\left(s, x_{D}\right)$ for all $t \leq s \leq T^{d} \leq T^{p}$ and is, assuming $x>x_{D}$,

$$
\begin{aligned}
& V(t, x)=U(t, x)+B_{t}^{z} \hat{\mathbb{E}}_{t} {\left[\int_{t}^{T_{D} \wedge T^{d}} \frac{\tau_{s}^{*} R_{s}}{B_{s}^{z}} d s\right] } \\
&-\alpha B_{t}^{z} \hat{\mathbb{E}}_{t}\left[X_{\left\{\exists s \in\left[t, T^{d}\right], X_{s}=x_{D}\right\}} \frac{U\left(T_{D}, x_{D}\right)}{B_{T_{D}}^{z}}\right]
\end{aligned}
$$

where $T_{D}=\inf \left\{s \in\left[t, T^{d}\right], X_{s}=x_{D}\right\}$, is the first time $X_{t}=x_{D}$, and $x_{A}$ is the indicator function for event $A .^{29}$

In the right-hand-side of equation (3.14), the second term is the tax shield taking into account the risk it is lost in case of default, i.e. the first time the process $X_{t}$ hits $x_{D}$ from above; the third term is the value of the bankruptcy costs incurred at the date of default, which are proportional to the current value of the unlevered asset. Equation (3.14) can be easily implemented using some numerical methods.

In subsequent sections we will need also $D$, the market value of corporate bonds, in the generalized Miller equilibrium economy. As above, we denote $R$ the coupon payment and $P$ the principal payment (face value) paid back at maturity $T^{d}$. Under the assumption of exogenous default at the threshold $x_{D}$, debt is a contingent claim on $X$, the EBIT of the firm. The next proposition determines, under the hypothesis of a generalized Miller equilibrium, the value of defaultable debt.

Proposition 7. The market value of debt satisfies equation

$$
\frac{1}{2} \sigma^{2}(X, t) \frac{\partial^{2} D}{\partial X^{2}}+g(X, t) \frac{\partial D}{\partial X}+\frac{\partial D}{\partial t}+R_{t}=r^{f} D
$$

with boundary conditions $D\left(T^{d}, X_{T^{d}}\right)=P, D\left(s, x_{D}\right)=(1-\alpha) U\left(s, x_{D}\right)$ for all $t \leq s \leq T^{d} \leq T^{p}$ and, assuming $x>x_{D}$, is

$$
\begin{aligned}
D(t, x)=B_{t}^{f} \hat{\mathbb{E}}_{t}\left[\int_{t}^{T_{D} \wedge T^{d}} \frac{R_{s}}{B_{s}^{f}} d s\right]+B_{t}^{f} \hat{\mathbb{E}}_{t}\left[\chi_{\left\{\forall s \in\left[t, T^{d}\right], X_{s}>x_{D}\right\}} \frac{P}{B_{T^{d}}^{f}}\right] \\
+(1-\alpha) B_{t}^{f} \hat{\mathbb{E}}_{t}\left[\chi_{\left\{\exists s \in\left[t, T^{d}\right], X_{s}=x_{D}\right\}} \frac{U\left(T_{D}, x_{D}\right)}{B_{T_{D}}^{f}}\right]
\end{aligned}
$$

\footnotetext{
${ }^{29} \chi_{A}(\omega)=1$ if $\omega \in A, \chi_{A}(\omega)=0$ otherwise. We denote $x \wedge y=\inf \{x, y\}$.
} 
where $T_{D} \leq T^{d}$ is the first time $X_{t}=x_{D}$.

As in the default-free case, we will introduce more restrictive assumptions on our model in order to derive convenient closed-form formulas for the sake of the subsequent analysis. Hence, $\tau^{c}, \tau^{e}, \tau^{b}, r^{f}, r^{z}$ are constant; moreover, in (3.1) $g(X, t)=g X, \sigma(X, t)=\sigma X$, and $g$ and $\sigma$ are constant; lastly, we assume that the operations are financed with a coupon bond with constant coupon payment, $R$, and principal, $P$, payable at maturity $T^{d} \leq T^{p}$. This is the Modigliani and Miller (1958) constant debt extended to the case of defaultable debt.

Under these assumptions, from (3.14) and considering the analytic formula for the density of the hitting time $T_{D}$, the value of the firm is, for $x>x_{D},{ }^{30}$

$$
\begin{gathered}
V(t, x)=U(t, x)+\frac{\tau^{*} R}{r^{z}}-\left(\frac{\tau^{*} R}{r^{z}}+\frac{\alpha x_{D}\left(1-\tau^{c}\right)}{r^{z}-g}\right) G\left(T^{d}, x_{D}, x, t, r^{z}\right) \\
+\frac{\alpha x_{D}\left(1-\tau^{c}\right)}{r^{z}-g} e^{-\left(r^{z}-g\right)\left(T^{p}-t\right)} G\left(T^{d}, x_{D}, x, t, g\right) \\
\quad-\frac{\tau^{*} R}{r^{z}} e^{-r^{z}\left(T^{d}-t\right)}\left(1-H\left(T^{d}, x_{D}, x, t\right)\right)
\end{gathered}
$$

where $U(t, x)$ is defined in equation (3.9),

$$
\begin{aligned}
H\left(T^{d}, x_{D}, x, t\right) & \left.=\mathcal{N}\left(-p_{1}\right)\right)+\mathcal{N}\left(-p_{2}\right)\left(\frac{x}{x_{D}}\right)^{2 g / \sigma^{2}-1} \\
p_{1} & =\frac{\log \frac{x}{x_{D}}+\left(g-\frac{\sigma^{2}}{2}\right)\left(T^{p}-t\right)}{\sigma \sqrt{T^{d}-t}}, \\
p_{2} & =\frac{\log \frac{x}{x_{D}}-\left(g-\frac{\sigma^{2}}{2}\right)\left(T^{p}-t\right)}{\sigma \sqrt{T^{d}-t}},
\end{aligned}
$$

with $\mathcal{N}(\cdot)$ denoting the cumulative Normal distribution, and where

$$
G\left(T^{d}, x_{D}, x, t, r\right)=\left(\frac{x}{x_{D}}\right)^{\beta_{1}(r)} \mathcal{N}\left(-q_{1}(r)\right)+\left(\frac{x}{x_{D}}\right)^{\beta_{2}(r)} \mathcal{N}\left(-q_{2}(r)\right),
$$

with

$$
\beta_{1}(r)=-\left(\frac{g}{\sigma^{2}}-\frac{1}{2}\right)+\sqrt{\left(\frac{g}{\sigma^{2}}-\frac{1}{2}\right)^{2}+2 \frac{r}{\sigma^{2}}}>1,
$$

\footnotetext{
${ }^{30}$ This formula is derived in Appendix A.
} 


$$
\begin{aligned}
& \beta_{2}(r)=-\left(\frac{g}{\sigma^{2}}-\frac{1}{2}\right)-\sqrt{\left(\frac{g}{\sigma^{2}}-\frac{1}{2}\right)^{2}+2 \frac{r}{\sigma^{2}}}<0, \\
& q_{1}(r)=\frac{\log \frac{x}{x_{D}}+\sqrt{2 r \sigma^{2}+\left(g-\frac{\sigma^{2}}{2}\right)^{2}}\left(T^{d}-t\right)}{\sigma \sqrt{T^{d}-t}}, \\
& q_{2}(r)=\frac{\log \frac{x}{x_{D}}-\sqrt{2 r \sigma^{2}+\left(g-\frac{\sigma^{2}}{2}\right)^{2}}\left(T^{d}-t\right)}{\sigma \sqrt{\left(T^{d}-t\right)}} .
\end{aligned}
$$

Note that in equation (3.17), for $x>x_{D}, V(t, x)>0$.

In Section 5 we will need also the value of the tax shield and debt in the defaultable case under the more restrictive assumptions introduced above. As for the tax shield, from equation (3.17) we have

$$
\begin{aligned}
T S(t, x)=\frac{\tau^{*} R}{r^{z}}-\frac{\tau^{*} R}{r^{z}} & G\left(T^{d}, x_{D}, x, t, r^{z}\right) \\
& -\frac{\tau^{*} R}{r^{z}} e^{-r^{z}\left(T^{d}-t\right)}\left(1-H\left(T^{d}, x_{D}, x, t\right)\right)
\end{aligned}
$$

where $H$ and $G$ are defined respectively in (3.18) and (3.19).

As for debt, from Proposition 7:

$$
\begin{aligned}
D(t, x)=\frac{R}{r^{f}}- & \frac{R}{r^{f}} G\left(T^{d}, x_{D}, x, t, r^{f}\right) \\
+ & e^{-r^{f}\left(T^{d}-t\right)}\left(P-\frac{R}{r^{f}}\right)\left(1-H\left(T^{d}, x_{D}, x, t\right)\right) \\
& +\frac{(1-\alpha) x_{D}\left(1-T^{c}\right)}{r^{z}-g}\left(G\left(T^{d}, x_{D}, x, t, r^{f}\right)\right. \\
& \left.+e^{-\left(r^{z}-g\right)\left(T^{p}-t\right)} G\left(T^{d}, x_{D}, x, t, g+r^{f} T^{m}\right)\right)
\end{aligned}
$$

where $H$ and $G$ are defined respectively in (3.18) and (3.19). The valuation formula for bond in (3.21) should be compared to the ones in Leland (1994, Eq. (7)) and Leland and Toft (1996, Eq. (3)). The first difference with respect to those formulas are that here the value driver is the EBIT process, whereas there the driver is the value of the asset. More important is the difference induced by the differential taxation of equity flows and bond flows. ${ }^{31}$

\footnotetext{
${ }^{31}$ In Leland (1994, Footnote 27), personal taxation is introduced into the model, and the effective tax advantage to debt, $\tau^{*}$, is used in place of the corporate tax rate, $\tau^{c}$. Nevertheless, the same risk-free rate is used for valuing equity flows, like the tax shield, and bond flows, like the coupon payment.
} 
If the firm/project and the debt are perpetual, $T^{d}=T^{p}=\infty$, then (3.17) simplifies to ${ }^{32}$

$$
V(x)=U(x)+\frac{\tau^{*} R}{r^{z}}\left(1-\left(\frac{x}{x_{D}}\right)^{\beta_{2}\left(r^{z}\right)}\right)-\frac{\alpha x_{D}\left(1-\tau^{c}\right)}{r^{z}-g}\left(\frac{x}{x_{D}}\right)^{\beta_{2}\left(r^{z}\right)}
$$

for $x>x_{D}$ and where $U(x)=x\left(1-\tau^{c}\right) /\left(r^{z}-g\right)$, and (3.21) is reduced to $^{33}$

$$
D(x)=\frac{R}{r^{f}}+\left(\frac{(1-\alpha) x_{D}\left(1-\tau^{c}\right)}{r^{z}-g}-\frac{R}{r^{f}}\right)\left(\frac{x}{x_{D}}\right)^{\beta_{2}\left(r^{f}\right)}
$$

for $x>x_{D} \cdot{ }^{34}$

\section{Valuation of real options when the debt policy is exogenous}

This section addresses real options valuation under the general framework introduced in Section 2, assuming that an exogenous debt policy is given and the tax shield may be valuable according to the analysis of Section 3. In particular, we will differentiate our analysis according to the cases of default-free debt and defaultable debt.

We have the opportunity to delay investment in a project, ${ }^{35}$ whose incremental EBIT follows the stochastic process in (3.1) under the EMM.

32 Alternatively, equation (3.22) can be derived also considering that, under the simplifying assumptions introduced above and since $V$ is independent of time because the horizon is infinite, then the valuation pde in (3.4) reduces to

$$
\frac{1}{2} \sigma^{2} X_{t}^{2} V_{x x}+g X_{t} V_{x}+X_{t}\left(1-\tau^{c}\right)+\tau^{*} R=r^{z} V .
$$

where subscripts of $V$ denote partial derivatives. The general solution for this pde is $V(x)=A x^{\beta_{2}\left(r^{z}\right)}+\left(1-\tau^{c}\right) x /\left(r^{z}-g\right)+\tau^{*} R / r^{z}$. By imposing the value-matching condition, for $X_{t}=x_{D}, V\left(x_{D}\right)=(1-\alpha)\left(1-\tau^{c}\right) x_{D} /\left(r^{z}-g\right)$, we solve for $A$ and, by replacing $A$ into the expression of the general solution we obtain (3.22).

${ }^{33}$ The derivation of equation (3.23) can be done following the same argument used in Footnote 32.

${ }^{34}$ It is possible to extend the discussion of the infinite horizon case to incorporate an endogenous default, by selecting a threshold $x_{D}$ such that the value of equity is maximized. This entails first the valuation of debt and next the valuation of equity. Then by imposing the smooth-pasting condition on equity, the optimal value of $x_{D}$ would be determined. For brevity we skip this part. The related equations are available from the Authors on request.

${ }^{35}$ For definiteness, we will discuss the prototypical case of the option to delay an 
The project has duration $T^{p}$ (possibly, $T^{p}=\infty$ ), so that the project starts from the date the option is exercised, $T_{I}$, and ends at $T_{I}+T^{p}$. The cost to implement the project is $I$ (an adapted process) and we have the opportunity to delay the investment until date $T^{o}\left(\right.$ possibly, $\left.T^{o}=\infty\right) .^{36}$

We assume that the capital expenditure to implement the project is financed also with incremental debt, and the incremental debt is issued if and when the option to invest is exercised. ${ }^{37}$ This assumption is realistic since there would be no reason to raise capital before investment, so incurring in a (useless) opportunity cost of capital. The optimal exercise policy depends on $X_{t}$, the EBIT process, and consequently the date we will issue debt is a stopping time. Issuance of incremental debt is contingent on the decision to invest, so yielding that the financing decision is influenced by the investment decision. On the other hand, the investment decision is influenced by the financing decision, since the former is made if the expected free cash flow from the project can remunerate the cost of capital. The debt policy is alternatively the one in Section 3.2 (defaultfree) or the one in Section 3.3 (defaultable). The debt has duration $T^{d}$, so that it is issued at $T_{I}$ and is paid-back at $T_{I}+T^{d}$.

The value of the levered project, at the date it is implemented, is $V\left(t, X_{t}\right)$ from equation (3.5) in the case with default-free debt or from equation (3.14) with defaultable debt. In case default is possible, given the above assumption that debt is issued conditional on the investment decision, we assume that default can happen only after the investment date. Let $\Pi$ denote the payoff of the option at the exercise date,

$$
\Pi\left(t, X_{t}\right)=\max \left\{V\left(t, X_{t}\right)-I, 0\right\},
$$

and let $F\left(t, X_{t}\right)$ denote the value of the investment project including the time-value of the option to postpone the decision.

investment decision, although our approach can be applied to a broader class of real options. See Dixit and Pindyck (1994) and Trigeorgis (1996) for a general classification of real options.

${ }^{36}$ To simplify our analysis, we assume perfect information of shareholders and equity-holders and the absence of agency costs between shareholders and equityholders and equity-holders and management. Hence, investment is implemented under a first-best investment policy (i.e., a policy aiming at maximizing the total project/firm value as opposed to a policy in the sole interest of shareholders) by the managers. The role of agency costs of debts on investment decisions have been analyzed among others by Mello and Parsons (1992), Mauer and Ott (2000) and Childs et al. (2000).

${ }^{37}$ Mauer and Ott (2000) and Childs et al. (2000) assume that the incremental investment is financed only with equity. Their assumption is included in our framework by posing that no incremental debt is issued at the time the investment decision is made. 
Proposition 8. The value of the option to invest satisfies equation

$$
\frac{1}{2} \sigma^{2}\left(X_{t}, t\right) \frac{\partial^{2} F}{\partial X^{2}}+g\left(X_{t}, t\right) \frac{\partial F}{\partial X}+\frac{\partial F}{\partial t}=r^{z} F
$$

with boundary condition $F\left(T_{I}, X_{T_{I}}\right)=\Pi\left(T_{I}, X_{T_{I}}\right)$, and is

$$
F(t, x)=B_{t}^{z} \sup _{T_{I}} \hat{\mathbb{E}}_{t}\left[\frac{\Pi\left(T_{I}, X_{T_{I}}\right)}{B_{T_{I}}^{z}}\right],
$$

where $T_{I} \leq T^{o}$ is the investment (stopping) time, i.e., the first time $F\left(t, X_{t}\right)=$ $\Pi\left(t, X_{t}\right)$.

If the investment option is owned by an ongoing firm, the CE discount factor for equity flows, $B^{z}$, is used to discount the expectation of the payoff independently of the financial structure while the option to delay investment is kept unexercised, which can be different from the capital structure of the firm after the project is implemented and from the current capital structure of the firm.

Equation (4.3) suggests that the option to invest in a marginal project (i.e., a project with corporate tax rate, $\tau^{c}$, equal to the marginal tax rate, $\tau_{m}$, and no tax shield $\tau^{*}=0$ ) is evaluated according to Black, Scholes, and Merton's formula, but using $r_{z}$ instead of $r_{f}$. Note that in our setting, since a project cannot be all-debt financed, $r_{f}$ is never used but when $\tau^{e}=\tau^{b}$ (which implies $\tau_{m}=0$ ).

\section{Debt and the investment policy}

In this section we will analyze the impact of the exogenous debt policy on the time-value of the option to delay investment and hence on the investment policy. Differently from the previous sections, the analysis in the current section will rely as much as possible on closed-form formulas for the value of the tax shields and for the value of the options. For this reason we will confine ourselves to the case with $\tau^{c}, \tau^{e}, \tau^{b}, r^{f}, r^{z}$ constant, and in (3.1), $g(X, t)=g X, \sigma(X, t)=\sigma X$, with constant $g$ and $\sigma$. This is done in the interest of simplicity, since otherwise we would have to present numerical valuations with no substantial additional economic insight. Moreover, since the tax shield is valuable when $\tau^{c}>\tau_{m}$, we will spell out the results for a supra-marginal firm/project, noticing that the result are of the opposite sign for an infra-marginal firm/project $\left(\tau^{c}<\tau_{m}\right)$. 
Starting from Proposition 8, which states the valuation principle for the option to delay investment assuming that the project is financed also with debt, we provide an approximate solution for equation (4.3) applying an analytic approximation akin the one MacMillan (1986) and BaroneAdesi and Whaley (1987) proposed for American options.

Assuming that the maturity of debt is equal to the maturity of the project, $T^{d}=T^{p}$, given $V(t, x)$, the value of the levered project from equations (3.10) and (3.11) (or, if the M-E debt policy is assumed, $D=L V$, from (3.12)) in the default-free case or from equation (3.17) in the defaultable case, we can approximate the value of the option to invest, $F(t, x)$ in (4.3), with payoff $\Pi\left(t, X_{t}\right)$ from (4.1) with constant $I$ and maturity $T^{o}$, using an analytic approximation. In the default-free case, we assume also that $k(t)$ in (3.11) is strictly positive, so that $V(t, x)>0 .{ }^{38}$ In defaultable case, we assume that $x>x_{D}$, so that $V(t, x)>0$.

Proposition 9. The value of the option to invest is approximated by

$$
\widetilde{F}(t, x)= \begin{cases}f(t, x)+\varphi x^{\eta}\left(1-e^{-r^{z}\left(T^{o}-t\right)}\right) & \text { if } x<x_{t}^{*} \\ V(t, x)-I & \text { if } x \geq x_{t}^{*}\end{cases}
$$

for given constants $\eta>1, \varphi>0$ and $x_{t}^{*}>0$, where

$$
f(t, x)=e^{-\left(r_{z}-g\right)\left(T^{o}-t\right)} \mathcal{N}\left(m_{1}\right) V(t, x)-e^{r_{z}\left(T^{o}-t\right)} \mathcal{N}\left(m_{2}\right) I
$$

is the value of the (related) European option with maturity $T^{o}$ and payoff $\Pi\left(t, X_{t}\right)$ from (4.1), with

$$
m_{1}=\frac{\log \frac{V(t, x)}{I}+\left(g+\frac{\sigma^{2}}{2}\right)\left(T^{o}-t\right)}{\sigma \sqrt{T^{o}-t}}, \quad m_{2}=m_{1}-\sigma \sqrt{T^{o}-t} .
$$

Note that $x_{t}^{*}$ in Proposition 9 depends on $t$. This means that the above approximation must be done at any time $0 \leq t \leq T^{o}$ to properly define a time-dependent investment policy, $\left\{x_{t}^{*}\right\}$.

To analyze also the effect of the debt policy on the exercise policy, we compute the probability of investing (assuming that currently the opportunity is still available) within the time horizon $T^{o}$. Since the probability we are interested in is under the actual measure, and not under the EMM,

\footnotetext{
${ }^{38}$ Sufficient conditions for $k(t)>0$ for a supra-marginal firm/project are $r^{z}-$ $r^{f} \tau^{*} L>g$ and $\tau^{*}>0$. See also footnote 27 .
} 
we have to compute the risk premium, denoted $\Phi$, for the stochastic process $X_{t} \cdot{ }^{39}$ We will denote $\hat{g}=g+\Phi$ the drift for process $X_{t}$ under the actual probability measure.

At $t$, assuming that the option to defer has not been exercised yet, this is equivalent to compute the probability that $X_{t}$ touches (from below) the investment threshold $\left\{x_{s}^{*} \mid t<s \leq T\right\}$, as computed using the approximation introduced in Proposition 9. According to Harrison (1985, pp. 11-14) this probability is ${ }^{40}$

$$
H\left(T^{o}, x_{t}^{*}, x, t\right)=\mathcal{N}\left(p_{1}\right)+\mathcal{N}\left(p_{2}\right)\left(\frac{x_{t}^{*}}{x}\right)^{2 \hat{g} / \sigma^{2}-1}
$$

where

$$
p_{1}=\frac{\log \frac{x}{x_{t}^{*}}+\left(\hat{g}-\frac{\sigma^{2}}{2}\right)\left(T^{o}-t\right)}{\sigma \sqrt{T^{o}-t}}, \quad p_{2}=p_{1}-\left(\frac{2 \hat{g}}{\sigma^{2}}-1\right) \sigma \sqrt{T^{o}-t} .
$$

Equations (5.1) and (5.2) simplify if we assume that the time-horizon for the project, the debt, and the investment option is infinite: $T^{p}=T^{d}=$ $T^{o}=\infty$.

In the default-free case, (5.1) becomes ${ }^{41}$

$$
F(x)=\left\{\begin{array}{ll}
\frac{K x^{*}}{\eta}\left(\frac{x}{x^{*}}\right)^{\eta} & x<x^{*} \\
K x-I & x \geq x^{*}
\end{array}, \quad \text { where } \quad x^{*}=\frac{\eta}{\eta-1} \frac{I}{K}\right.
$$

where $K=\left(1-\tau^{c}\right) /(\rho-g)$ from equation (3.12) when assuming $T^{p}=$ $T^{d}=T^{o}=\infty$.

In case debt is defaultable, (5.1) becomes

$$
\begin{aligned}
& F(x)= \\
& \begin{cases}\frac{1}{\beta_{1}}\left(\frac{x\left(1-\tau^{c}\right)}{r^{z}-g}-\beta_{2}\left(\frac{x}{x_{D}}\right)^{\beta_{2}}\left(\frac{\tau^{*} R}{r^{z}}+\frac{\alpha x_{D}\left(1-\tau^{c}\right)}{r^{z}-g}\right)\right)\left(\frac{x}{x^{*}}\right)^{\beta_{1}} & \text { if } x_{D} \leq x<x^{*} \\
V(t, x)-I & \text { if } x>x^{*},\end{cases}
\end{aligned}
$$

\footnotetext{
${ }^{39}$ In Appendix A, we present a way to determine the risk premium for the EBIT process, $X_{t}$.

${ }^{40}$ Actually, $\widetilde{P}$ is the probability of the first time $X_{t}=x_{t}^{*}$, with initial condition $x_{t}<x_{t}^{*}$. Nevertheless, $x_{t}^{*}$ is the current investment threshold. Since $x_{s}^{*}$ is decreasing over time, $H$ in equation (5.2) is actually a lower bound for the probability of investing.

${ }^{41}$ Note that in this case the solution is exact and not approximated: $F^{\infty}=F$.
} 
where $V(t, x)$ is defined in equation (3.22) and $x^{*}$ is the root of equation $^{42}$

$$
\frac{1}{\beta_{1}}\left(\frac{x\left(1-\tau^{c}\right)}{r^{z}-g}-\beta_{2}\left(\frac{x}{x_{D}}\right)^{\beta_{2}}\left(\frac{\tau^{*} R}{r^{z}}+\frac{\alpha x_{D}\left(1-\tau^{c}\right)}{r^{z}-g}\right)\right)=V(t, x)-I,
$$

and is independent of $t$.

Also (5.2) considerably simplifies when $T^{p}=T^{d}=T^{o}=\infty$. By straightforward algebra, the actual probability of investing simplifies to ${ }^{43}$

$$
H\left(x^{*}, x\right)= \begin{cases}1 & \text { if } \hat{g}-\sigma^{2} / 2 \geq 0 \\ \left(\frac{x^{*}}{x}\right)^{\frac{2 \hat{g}}{\sigma^{2}}-1} & \text { if } \hat{g}-\sigma^{2} / 2<0\end{cases}
$$

when $x<x^{*}$, with $\hat{g}=g+\Phi$, where $x^{*}$ can be either the one in (5.3) in the default-free case or the one in (5.4) in the defaultable case.

In the infinite horizon case $\left(T^{p}=T^{d}=T^{o}=\infty\right)$, it is easy to check that, for a supra-marginal project/firm $\left(\tau^{*}>0\right)$, assuming that debt is default-free, the value of the option to invest and the probability of investing are increasing function of leverage, $L$. Actually, $F$ and $x^{*}$ in equation (5.3) are respectively increasing and decreasing with respect to $K$, and $K$ is an increasing function of $L$. Moreover, $H$ from equation (5.5) is a decreasing function of $x^{*}$. The opposite is true for an infra-marginal project. As we can see from subsequent numerical analysis, this is confirmed also in the finite horizon case. Things are completely different in the case with defaultable debt. To show this we will resort to numerical analysis.

In the finite horizon case, we will analyze the effect of debt and uncertainty on the APV, on the value of the option to defer and on the exercise policy, in the supra-marginal case $\tau^{*}>0$, by discussing a numerical example and running a sensitivity analysis of the APV, of the value of the real option and of the probability of investing on the uncertainty of EBIT, $\sigma$, and on the level of debt. It is easy to check that $\widetilde{F}$ and $\widetilde{P}$ are not affected by the debt policy when $\tau^{*}=0 .{ }^{44}$ Although we chose a specific set of parameters for presentation purposes, the results we show are general. The base case parameters are in Table 1.

\footnotetext{
${ }^{42}$ This equation must be solved numerically.

${ }^{43}$ Since the investment threshold, $x^{*}$, is independent of $t$, the valuation formula for probability is exact.

${ }^{44}$ This is a motivation for having introduced the general Miller equilibrium framework where tax shields may be valuable.
} 
[Table 1 about here]

For these parameters, $\tau^{*}=\tau^{c}-\tau^{m}>0$. Moreover, the APV of the project in the default-free case is, from equation (3.12), $V=5.014$ and the market value of debt is $D=L \cdot V \approx 2.858$. On the other hand, in the defaultable case, the APV of the project, from equation (3.17), is $V=5.197$ and the market value of debt is, from equation (3.21), $D=$ 2.960. We set the face value of debt $P \approx R / r^{f}$. To make the values in the defaultable case comparable to the values in the default-free case, we set the same initial debt proportion (at market values), $L=D / V=0.569 \approx$ 0.57 , for both cases.

In the subsequent analyses we will make debt (i.e., total coupon payment, $R$ ) vary in a given range: accordingly, in the defaultable case, we will assume that the default threshold $x_{D}$ is always equal to $R$. Hence, for the given EBIT rate, $x=1$, the higher $R$ the closer to default is the firm/project.

The first analysis concerns the effect of uncertainty and debt on the APV and on the value of the tax shield. From Figure 1 (above) we can see that in the default-free (M-E) case, leverage has always a positive effect and uncertainty has no role in valuation. ${ }^{45}$ The outcome is completely different in the defaultable case, Figure 1 (below). Here both uncertainty and leverage have a role: for any level of uncertainty, there is a debt level (represented by total coupon payment, $R$ ) that maximizes the APV. Moreover, the lower the uncertainty the higher the optimal level of debt. For high uncertainty and debt, the APV becomes negligible. For further clarification, in Figure 2 (above) we plot the tax shield from equation (3.20) for the same range of values for $\sigma$ and $R$. This shows that the humped-shape of the APV is due to the tax shield. Actually, the base value (Figure 2 (below)), defined as the APV less the tax shield, is almost constant when $R$ is low and default is unlikely and become negligible when $R$ is large and default is almost certain. The above represents a generalization of the results provided by Brennan and Schwartz (1978).

[Figure 1 about here]

[Figure 2 about here]

\footnotetext{
${ }^{45}$ In our computations we are assuming that the additional uncertainty does not affect the risk premium, and hence does not change the value of the project. On the other hand, if there was an increment in systematic risk, the APV would be reduced. We are not interested here to capture this effect in our analysis and concentrate on the effect of uncertainty on the tax shield.
} 
We next explore the effect of uncertainty and debt on the value of the real option to invest. From Figure 3 (above), it can be seen that, in the default-free case, both volatility and leverage have a positive effect on the value of the real option to invest. This can be easily explained by observing that a higher leverage increases the tax shield and the APV of the project, so increasing also the value of the option. On the other hand, as usual, higher volatility increases the time value of the option. In case of defaultable debt (see Figure 3 (below)), the effect of debt and uncertainty is different from the default-free case. Still, for every level of uncertainty, there is an optimal debt level which maximizes the value of the option to invest. This is mostly due to the effect of the tax shield on the APV of the project, which is the underlying asset of the option. Yet, for low leverage, the value of the option to invest is an increasing function of volatility, since the increased time value dominates the reduction of value of tax shield due to the higher probability of default. On the other hand, for high leverage, the value of the option to delay investment is not a monotonic function of volatility of EBIT: when volatility is low, it is the positive effect of lower default probability that dominates; when volatility is high, it is the higher time value that dominates. By comparing Figure 1 (below) and Figure 3 (below), we can see that the additional value is the time-value of the option.

[Figure 3 about here]

Lastly, we analyze the probability of exercising the real option to delay investment. As noted above, both in the default-free case and in the defaultable case, uncertainty increases the time-value of the option, so it is natural to ask whether also the probability of investing is increased. In Figure 4 we plot the probability of investing before maturity in the default-free case (above) and defaultable case (below). In the first case, leverage increases the probability of investing for any level of uncertainty, because the higher the leverage, the more risk is transferred to bond-holders; on the other hand, for a given leverage, uncertainty first has a positive and then a negative effect on the probability of investing. ${ }^{46}$ In the defaultable case (Figure 4 (below)), the effect of debt is positive only when $\sigma$ is low. Otherwise we have that, when the probability of default is large (high coupon), more debt reduced the probability of investing and uncertainty has only a negative effect.

${ }^{46}$ This behavior of the probability of investing with respect to volatility of the valuedriver is well know. See Sarkar (2000) and Cappuccio and Moretto (2001) for more details. 
[Figure 4 about here]

\section{Acknowledgements}

The authors gratefully acknowledges the financial support of TransAlta Research Visiting Scholar Program, Faculty of Management, University of Calgary, the financial support of the University of Navarra and the financial support of University of Verona.

We thank Alex Triantis, Steve Heston, Martino Grasselli, and the participants at the International Conference of Finance, Hammamet 2003, at the 7th Real Options Conference, Washington (DC) 2003, at the Northern Finance Association conference, Quebec City 2003, at the Conference on Quantitative Methods in Finance, Sydney 2003, and of the seminar at the University of Maryland, April 2003, for their insightful comments. Any remaining errors are our own. 


\section{References}

Auerbach, A. J. (1991). Retrospective capital gain taxation. American Economic Review, 81(1):167-178.

Auerbach, A. J. and Bradford, D. (2001). Generalized cash flow taxation. Technical Report 8122, National Boreau of Economic Research.

Barone-Adesi, G. and Whaley, R. (1987). Efficient analytic approximation of American option values. Journal of Finance, 42:301-320.

Brennan, M. J. and Schwartz, E. S. (1978). Corporate income taxes, valuation, and the problem of optimal capital structure. Journal of Business, 51(1):103-114.

Cappuccio, N. and Moretto, M. (2001). Comments on the investmentuncertainty relationship in a real option model. working paper 282001, Fondazione ENI Enrico Mattei.

Childs, P. D., Mauer, D. C., and Ott, S. H. (2000). Interaction of corporate financing and investment decisions: The effect of growth options to exchange or expand. presented at the $4^{\text {th }}$ Annual Conference on Real Options, University of Cambridge.

Christensen, P. O., Flor, C. R., Lando, D., and Miltersen, K. R. (2002). Dynamic capital structure with callable debt and debt renegotiations. Technical report, Norvegian School of Economics and Business Administration.

Constantinides, G. M. (1983). Capital market equilibrium with personal tax. Econometrica, 51:611-636.

Dangl, T. and Zechner, J. (2003). Credit risk and dynamic capital structure choice. Technical Report 4132, CEPR.

Dixit, A. and Pindyck, R. (1994). Investment Under Uncertainty. Princeton University Press, Princeton, NJ.

Duffie, D. (2001). Dynamic Asset Pricing Theory. Princeton University Press, Princeton - NJ, third edition.

Fisher, E. O., Heinkel, R., and Zechner, J. (1989). Dynamic capital structure choice: Theory and tests. Journal of Finance, 44(1):19-40. 
Goldstein, R., Ju, N., and Leland, H. (2001). An EBIT-based model of dynamic capital structure. Journal of Business, 74(4340-01):483-512.

Grinblatt, M. and Liu, J. (2002). Debt policy, corporate taxes, and discount rates. Technical report, Anderson School at UCLA.

Harrison, J. (1985). Brownian Motion and Stochastic Flow Systems. Krieger, Malabar, Fl.

Jensen, B. A. (2003). On valuation before and after tax in no arbitrage models: tax neutrality in the discrete time model. Technical report, Dept. of Finance - Copenhagen Business School.

Lamberton, D. and Lapeyre, B. (1996). Introduction to Stochastic Calculus Applied to Finance. Chapman \& Hall, London, UK.

Leland, H. E. (1994). Corporate debt value, bond covenants, and optimal capital structure. Journal of Finance, 49(4):1213-1252.

Leland, H. E. and Toft, K. B. (1996). Optimal capital structure, endogenous bankruptcy, and the term structure of credit spreads. Journal of Finance, 51(3):987-1019.

MacMillan, L. (1986). Analytic approximation for the American put option. Advances in Futures and Options Research, 1:119-139.

Mauer, D. C. and Ott, S. H. (2000). Agency costs, underinvestment, and optimal capital structure. In Brennan, M. J. and Trigeorgis, L., editors, Project flexibility, Agency, and Competition, pages 151-179, New York, NY. Oxford University Press.

Mauer, D. C. and Triantis, A. J. (1994). Interaction of corporate financing and investment decisions: A dynamic framework. Journal of Finance, 49(4):1253-1277.

Mello, S. A. and Parsons, J. E. (1992). Measuring the agency cost of debt. Journal of Finance, 47(5):1887-1904.

Merton, R. C. (1973). Theory of rational option pricing. Bell Journal of Economics and Management Science, 4:141-183.

Merton, R. C. (1974). On the pricing of corporate debt: The risk structure of interest rates. Journal of Finance, 29(2):449-470. 
Miles, J. A. and Ezzell, J. R. (1980). The weighted average cost of capital, perfect capital markets, and project life: a clarification. Journal of Financial and Quantitative Analysis, 15(3):719-730.

Miles, J. A. and Ezzell, J. R. (1985). Reformulating tax shield valuation: A note. Journal of Finance, 40(5):1485-1492.

Miller, M. H. (1977). Debt and taxes. Journal of Finance, 32:261-275.

Modigliani, F. and Miller, M. H. (1958). The cost of capital, corporation finance and the theory of investment. American Economic Review, 48(3):261-297.

Modigliani, F. and Miller, M. H. (1963). Corporate income taxes and the cost of capital: a correction. American Economic Review, 53(3):433443.

Myers, S. C. and Majluf, N. (1984). Corporate financing and investment decisions when firms have information that investors do not have. Journal of Financial Economics, 5:187-221.

Reiner, E. and Rubinstein, M. (1991). Breaking down the barriers. RISK, $4: 28-35$.

Ross, S. A. (1976). The arbitrage theory of capital asset pricing. Journal of Economic Theory, 13:341-360.

Ross, S. A. (1987). Arbitrage and martingales with taxation. Journal of Political Economy, 95:371-393.

Sarkar, S. (2000). On the investment-uncertainty relationship in a real options model. Journal of Economic Dynamics \& Control, 24:219-225.

Sharpe, W. F. (1964). Capital asset prices: A theory of market equilibrium under condition of risk. Journal of Finance, 19:425-442.

Sick, G. (1990). Tax-adjusted discount rates. Management Science, 36:1432-1450.

Trigeorgis, L. (1993). Real option and interactions with financial flexibility. Financial Management, 22(3):202-224.

Trigeorgis, L. (1996). Real Options: managerial flexibility and strategy in resource allocation. MIT Press, Cambridge, MA. 


\section{A Proofs of propositions}

\section{Proof of Proposition 1}

For simplicity, we first prove the Proposition for equity assuming that no dividend is paid. Then we extend the result to the case that dividend are actually paid. Finally, we extend the result to the money market account.

If there is no dividend ( $X=0)$, we first observe that setting $t=T^{\prime}$ in equation (2.8) establishes that the two stock price processes are the same at time $T^{\prime}: S_{T^{\prime}}=S_{T^{\prime}}^{\text {at }}$. We will show that the price in (2.7) and the price in (2.8) obey the same dynamic equation (under $\mathbb{Q}$ ) with the riskless discount rate for equity $r^{z}$ :

$$
\hat{\mathbb{E}}_{t}\left[d S_{t}\right]=r_{t}^{z} S_{t} d t
$$

and

$$
\hat{\mathbb{E}}_{t}\left[d S_{t}^{\mathrm{at}}\right]=r_{t}^{z} S_{t}^{\mathrm{at}} d t
$$

Then, by the Feynman-Kac solution to the valuation equation (see, e.g. Duffie (2001, Ch. 5)), the security prices at a date $t \leq T^{\prime}$ are the riskneutral expectations of the common terminal value $S_{T^{\prime}}^{\text {at }}=S_{T^{\prime}}$

$$
\begin{aligned}
S_{t} & =B_{t}^{z} \hat{\mathbb{E}}_{t}\left[\frac{S_{T^{\prime}}}{B_{T^{\prime}}^{z}}\right] \\
& =S_{t}^{\mathrm{at}} .
\end{aligned}
$$

The proof that $S_{t}$ in equation (2.7) satisfies condition (A.1) is the standard martingale result. Thus, it remains to prove that $S_{t}^{\text {at }}$ defined in equation (2.8) satisfies the equivalent relation (A.2). From equation (2.8) we have, for small $\Delta t$,

$$
\begin{aligned}
\hat{\mathbb{E}}_{t}\left[S_{t+\Delta t}^{\mathrm{at}}\right] & =\hat{\mathbb{E}}_{t}\left[B_{t+\Delta t}^{z, \mathrm{at}} \hat{\mathbb{E}}_{t+\Delta t}\left[\frac{S_{T^{\prime}}}{B_{T^{\prime}}^{z, \mathrm{at}}}-\int_{t+\Delta t}^{T^{\prime}} \frac{\tau_{u}^{e}}{B_{u}^{z, \mathrm{at}}} d S_{u}^{\mathrm{at}}\right]\right] \\
& =\hat{\mathbb{E}}_{t}\left[B_{t+\Delta t}^{z, \mathrm{at}}\left(\frac{S_{T^{\prime}}}{B_{T^{\prime}}^{z, \mathrm{at}}}-\int_{t}^{T^{\prime}} \frac{\tau_{u}^{e}}{B_{u}^{z, \mathrm{at}}} d S_{u}^{\mathrm{at}}+\int_{t}^{t+\Delta t} \frac{\tau_{u}^{e}}{B_{u}^{z, \mathrm{at}}} d S_{u}^{\mathrm{at}}\right)\right] \\
& =\left(1+r_{t}^{z, \mathrm{at}} \Delta t\right)\left(S_{t}^{\mathrm{at}}+B_{t}^{z, \mathrm{at}} \hat{\mathbb{E}}_{t}\left[\int_{t}^{t+\Delta t} \frac{\tau_{u}^{e}}{B_{u}^{z, \mathrm{at}}} d S_{u}^{\mathrm{at}}\right]\right)+o(\Delta t) .
\end{aligned}
$$


Here $o(\Delta t)$ denotes terms that converge to zero as $\Delta t \rightarrow 0$. The second equality comes from breaking out the tax term for the interval $[t, t+\Delta t]$ and applying $\hat{\mathbb{E}}_{t}\left[\hat{\mathbb{E}}_{t+\Delta t}[\cdot]\right]=\hat{\mathbb{E}}_{t}[\cdot]$. The third equality comes from substituting for $S_{t}^{\text {at }}$ from (2.8) after using the following Taylor approximation for the riskless equity account value: ${ }^{47}$

$$
\begin{aligned}
B_{t+\Delta t}^{z, \text { at }} & =\exp \left(r_{t}^{z, \text { at }} \Delta t\right) B_{t}^{z, \text { at }}+o(\Delta t) \\
& =B_{t}^{z, \text { at }}\left(1+r_{t}^{z, \text { at }} \Delta t\right)+o(\Delta t)
\end{aligned}
$$

Since the tax rate $\tau_{u}^{e}$ varies continuously over time, we have that

$$
\int_{t}^{t+\Delta t} \frac{\tau_{u}^{e}}{B_{u}^{z, \mathrm{at}}} d S_{u}^{\mathrm{at}}=\frac{\tau_{t}^{e}\left(S_{t+\Delta t}^{\mathrm{at}}-S_{t}^{\mathrm{at}}\right)}{B_{t}^{z, \mathrm{at}}}+o(\Delta t),
$$

so we can rewrite (A.3) as:

$$
\hat{\mathbb{E}}_{t}\left[S_{t+\Delta t}^{\mathrm{at}}\right]=\left(1+r_{t}^{z, \mathrm{at}} \Delta t\right)\left(S_{t}^{\mathrm{at}}+\tau_{t}^{e} \hat{\mathbb{E}}_{t}\left[S_{t+\Delta t}^{\mathrm{at}}-S_{t}^{\mathrm{at}}\right]\right)+o(\Delta t) .
$$

Rearranging, we get

$$
\begin{aligned}
\left(1-\tau_{t}^{e}\right) \hat{\mathbb{E}}_{t}\left[S_{t+\Delta t}^{\mathrm{at}}-S_{t}^{\mathrm{at}}\right] & =r_{t}^{z, \text { at }} S_{t}^{\mathrm{at}} \Delta t+o(\Delta t) \\
& =r_{t}^{z}\left(1-\tau_{t}^{e}\right) S_{t}^{\mathrm{at}} \Delta t+o(\Delta t) .
\end{aligned}
$$

Since $\tau_{t}^{e}<1$, dividing by $\left(1-\tau_{t}^{e}\right)$ gives

$$
\hat{\mathbb{E}}_{t}\left[S_{t+\Delta t}^{\mathrm{at}}-S_{t}^{\mathrm{at}}\right]=r_{t}^{z} \Delta t S_{t}^{\mathrm{at}}+o(\Delta t) .
$$

By taking $\Delta t \rightarrow 0$ we get condition (A.2).

If dividends are paid, $(X \neq 0)$, the only thing that changes in the proof is that instead of (A.1), the dynamic condition is

$$
\hat{\mathbb{E}}_{t}\left[d S_{t}\right]+X_{t} d t=r_{t}^{z} S_{t}
$$

We must establish the analogue of (A.2), which is

$$
\hat{\mathbb{E}}_{t}\left[d S_{t}^{\mathrm{at}}\right]+X_{t} d t=r_{t}^{z} S_{t}^{\mathrm{at}} .
$$

\footnotetext{
${ }^{47}$ We are also using the fact that $r_{t}^{z \text {,at }}$ and $\tau_{t}^{e}$ are adapted.
} 
Inserting the after-tax dividend term in the analogue of (A.3) yields

$$
\begin{aligned}
\hat{\mathbb{E}}_{t}\left[S_{t+\Delta t}^{\mathrm{at}}\right]= & \left(1+r_{t}^{z, \mathrm{at}} \Delta t\right)\left(S_{t}^{\mathrm{at}}\right. \\
& \left.+B_{t}^{z, \mathrm{at}} \hat{\mathbb{E}}_{t}\left[-\int_{t}^{t+\Delta t} \frac{\left(1-\tau_{u}^{e}\right) X_{u}}{B_{u}^{z, \mathrm{at}}} d u+\int_{t}^{t+\Delta t} \frac{\tau_{u}^{e}}{B_{u}^{z, \mathrm{at}}} d S_{u}^{\mathrm{at}}\right]\right) \\
+ & o(\Delta t) \\
= & \left(1+r_{t}^{z, \mathrm{at}} \Delta t\right)\left(S_{t}^{\mathrm{at}}\right. \\
& \left.+B_{t}^{z, \mathrm{at}} \hat{\mathbb{E}}_{t}\left[-\left(1-\tau_{t}^{e}\right) \int_{t}^{t+\Delta t} \frac{X_{u}}{B_{u}^{z, \mathrm{at}}} d u+\int_{t}^{t+\Delta t} \frac{\tau_{u}^{e}}{B_{u}^{z, \mathrm{at}}} d S_{u}^{\mathrm{at}}\right]\right) \\
+ & o(\Delta t) .
\end{aligned}
$$

The first equality follows from the development of (A.3) and the second comes from the continuity of the tax rate $\tau_{u}^{e}$.

Rearranging as before, we have

$$
\left(1-\tau_{t}^{e}\right) \hat{\mathbb{E}}_{t}\left[S_{t+\Delta t}^{\mathrm{at}}-S_{t}^{\mathrm{at}}+\int_{t}^{t+\Delta t} \frac{X_{u}}{B_{u}^{z, \mathrm{at}}} d u\right]=r_{t}^{z}\left(1-\tau_{t}^{e}\right) S_{t}^{\mathrm{at}} \Delta t+o(\Delta t) .
$$

Dividing by $\left(1-\tau_{t}^{e}\right)$ and letting $\Delta t \rightarrow 0$ gives the desired result.

For the money market account, it is now straightforward to follow the same steps as above and show that

$$
\hat{\mathbb{E}}_{t}\left[d B_{t}\right]=d B_{t}=r_{f} B_{t} d t
$$

and

$$
\hat{\mathbb{E}}_{t}\left[d B_{t}^{\mathrm{at}}\right]=r_{f} B_{t}^{\mathrm{at}} d t
$$

The first is simply our definition of bond price dynamics. The second proof comes from appropriate modifications of the analogous result we just established for stocks. Since we defined the after-all-tax bond value so that it equals the bond value at $T^{\prime}$ (i.e. $B_{T^{\prime}}=B_{T^{\prime}}^{\text {at }}$, we can take the risk-neutral expectations to get the desired result:

$$
B_{t}=B_{t} \hat{\mathbb{E}}_{t}\left[\frac{B_{T^{\prime}}}{B_{T^{\prime}}}\right]=B_{t}^{\mathrm{at}}
$$




\section{Proof of Corollary 2}

Note that the proof of Proposition 1 started with a risk-neutral measure $\mathbb{Q}$ for stock $S_{t}$ before personal taxes and evaluated payoffs after personal taxes to derive a process of after-personal-tax stock prices $S_{t}^{\text {at }}$ using the same risk-neutral measure. This means that the CE operator is the same before and after tax.

\section{Proof of Proposition 4}

We will phrase the proof for a stock, but the argument is the same also for a money market account.

Since the argument for proving holding-period neutrality is not affected by the presence of dividends, because they are taxed at the date they are paid, we will assume for simplicity $X=0$ in equation (2.8). We define the tax account at $t$ as the value of the taxes on capital gains accrued until $t$ at the after-tax rate of return:

$$
A_{t}=B_{t}^{f, \text { at }} \int_{0}^{t} \frac{\tau_{u}^{e}}{B_{u}^{f, \text { at }}} d S_{u}
$$

By definition, equation (2.8) can be written as

$$
\frac{S_{t}}{B_{t}^{f, \mathrm{at}}}-\frac{A_{t}}{B_{t}^{f, \mathrm{at}}}=\hat{\mathbb{E}}_{t}\left[\frac{S_{T}}{B_{T}^{f, \mathrm{at}}}-\frac{A_{T}}{B_{T}^{f, \mathrm{at}}}\right] .
$$

Assume that at the (arbitrarily chosen) stopping time $t, 0 \leq t<T$ the investor decides to liquidate the position. The net proceeds are the price of the stock net of the taxes on capital gains accrued from $t=0$ until that date: $S_{t}-A_{t}$.

If $A_{t}>0$, then he can borrow an amount $A_{t}$ at an after-personal tax cost ${ }^{48}\left\{r_{u}^{f}\left(1-\tau_{u}^{b}\right)\right\}_{u=t}^{T}$ and with the proceeds he can buy the same stock at $S_{t}$. At $T$, by liquidating the position in the stock, he will receive $S_{T}-B_{T}^{f \text {,at }} \int_{t}^{T} \tau_{u}^{e} / B_{u}^{f, \text { at }} d S_{u}$ (i.e., the stock price less the tax on capital from $t$ to $T$ ), and paying back the loan, $-A_{t} B_{T}^{f \text {, at }} / B_{t}^{f \text {, at }}$, so that the net payoff

\footnotetext{
${ }^{48}$ This means that borrowing generates a tax saving proportional to $\tau^{b}$. Note that, from equilibrium, the after tax cost of borrowing is equal to $r^{z}\left(1-\tau^{e}\right)$.
} 
is

$$
\begin{aligned}
S_{T}-B_{T}^{f, \text { at }} \int_{t}^{T} & \frac{\tau_{u}^{e}}{B_{u}^{f, \text { at }}} d S_{u}-A_{t} \frac{B_{T}^{f, \text { at }}}{B_{t}^{f, \text { at }}} \\
& =S_{T}-B_{T}^{f, \text { at }} \int_{t}^{T} \frac{\tau_{u}^{e}}{B_{u}^{f, \mathrm{at}}} d S_{u}-B_{T}^{f, \text { at }} \int_{0}^{t} \frac{\tau_{u}^{e}}{B_{u}^{f, \mathrm{at}}} d S_{u}=S_{T}-A_{T}
\end{aligned}
$$

which is equal to the payoff of the buy-and-hold strategy over the interval $[0, T]$.

On the other hand, if $A_{t}<0$, then by liquidating the position at $t$, the amount $-A_{t}$ can be invested at the (after-personal tax) rate $\left\{r_{u}^{f}(1-\right.$ $\left.\left.\tau_{u}^{b}\right)\right\}_{u=t}^{T}$ over the interval $[t, T]$ and $S_{t}$ can be used to buy the same stock. By applying the same argument, at $T$ the net payoff is again $S_{T}-A_{T}$, which is the same of the buy-and-hold strategy.

\section{Proof of Proposition 5}

Consider the process for EBIT, under the actual probability measure,

$$
d X_{t}=\hat{g}\left(X_{t}, t\right) d t+\sigma\left(X_{t}, t\right) d Z_{t} .
$$

Since the EBIT process is not traded, for valuation purposes we assume that there is a spanning (twin) security/portfolio, whose price is denoted $S$, with process, under the actual probability measure,

$$
d S_{t}=\alpha\left(X_{t}, t\right) S_{t} d t+\beta\left(X_{t}, t\right) S_{t} d Z_{t}
$$

and dividend rate $\delta\left(X_{t}, t\right)$. Moreover, a money market account is available, with value $B^{f}$, following the process $d B^{f}=r_{t}^{f} B_{t}^{f} d t$.

To derive the valuation equation

$$
\frac{1}{2} \sigma^{2}(X, t) \frac{\partial^{2} V}{\partial X^{2}}+g(X, t) \frac{\partial V}{\partial X}+\frac{\partial V}{\partial t}+X_{t}\left(1-\tau_{t}^{c}\right)+\tau^{*} R_{t}=r_{t}^{z} V
$$

we employ the standard replicating argument introduced by Modigliani and Miller (1958) and extended to a continuous-time framework by Merton (1973), but on an after personal tax basis.

The rate of return of $V,{ }^{49}$ using Itô's Lemma, is (for notational sim-

\footnotetext{
${ }^{49}$ Note that, from (3.3), the value of the levered asset accrues to equity-holders, and hence is taxed at the tax rate for equity flows, $\tau^{e}$.
} 
plicity, we drop functional dependence when it is clear)

$$
\begin{aligned}
\frac{d V+X\left(1-\tau^{c}\right)+\tau^{*} R}{V}\left(1-\tau^{e}\right)= & \\
\frac{1}{V}\left(X\left(1-\tau^{c}\right)+\tau^{*} R+\frac{\partial V}{\partial t}+\hat{g} \frac{\partial V}{\partial X}+\right. & \left.\frac{1}{2} \sigma^{2} \frac{\partial^{2} V}{\partial X^{2}}\right)\left(1-\tau^{e}\right) d t \\
& +\frac{1}{V} \frac{\partial V}{\partial X} \sigma\left(1-\tau^{e}\right) d Z_{t}
\end{aligned}
$$

Taking a long position in a portfolio with price $W=n_{1} B^{f}+n_{2} S$ we obtain a rate of return

$$
\left(1-\frac{n_{2} S}{P}\right) r^{f}\left(1-\tau^{b}\right) d t+\frac{n_{2} S}{W}\left(\alpha+\frac{\delta}{S}\right)\left(1-\tau^{e}\right) d t+\frac{n_{2} S}{W} \beta\left(1-\tau^{e}\right) d Z_{t}
$$

Putting

$$
\frac{n_{2} S}{W}=\frac{\sigma}{\beta} \frac{\partial V / \partial X}{V}
$$

in (A.8), given the generalized Miller equilibrium relation (2.5) and after some manipulations, we have

$$
\frac{1}{2} \sigma^{2} \frac{\partial^{2} V}{\partial X^{2}}+\left(\hat{g}-\sigma \frac{\alpha+\delta / S-r^{z}}{\beta}\right) \frac{\partial V}{\partial X}+\frac{\partial V}{\partial t}+X\left(1-\tau^{c}\right)+\tau^{*} R=r^{z} V
$$

Considering the unit risk premium computed from the twin security/portfolio

$$
\lambda=\frac{\alpha+\delta / S-r^{z}}{\beta}
$$

we obtain equation (3.4) under the EMM, with $g=\hat{g}-\lambda \sigma$.

With condition $V\left(T^{d}, X_{T^{d}}\right)=U\left(T^{d}, X_{T^{d}}\right)$ and using the Feynman-Kac solution of (3.4), see Duffie (2001, pp. 340-346), we have (3.5).

\section{Proof of Proposition 6}

The proof that the APV satisfies equation (3.4) while $X_{t}>x_{D}$ is the same as in Proposition 5. Considering the boundary conditions $V\left(T^{d}, x\right)=$ $U\left(T^{d}, x\right)$ and $U\left(T^{p}, x\right)=0$ and $V\left(s, x_{D}\right)=(1-\alpha) U(s, X)$ for all $t \leq$ $s \leq T^{d}$, the existence of the solution of this problem follows from the application of a version of Feynman-Kac result for partial differential equations on open bounded sets, see Lamberton and Lapeyre (1996, Th. 5.1.9). 
For verification of (3.14), we define

$$
Y_{s}=\frac{B_{t}^{z}}{B_{S}^{z}} V\left(s, X_{s}\right) .
$$

By applying Itô's Lemma, we have

$$
\begin{aligned}
Y_{T_{D} \wedge T^{d}}=V(t, x)+\int_{t}^{T_{D} \wedge T^{d}} \frac{B_{t}^{z}}{B_{s}^{z}}\left(\frac{1}{2} \sigma^{2} \frac{\partial^{2} V}{\partial X^{2}}\right. & \left.+g \frac{\partial V}{\partial X}+\frac{\partial V}{\partial t}-r^{z} V\right) d s \\
& +\int_{t}^{T_{D} \wedge T^{d}} \frac{B_{t}^{z}}{B_{s}^{z}} \frac{\partial V}{\partial X} \sigma d Z_{s}
\end{aligned}
$$

We take expectations of both sides of (A.11) and note that:

$$
\begin{gathered}
\mathbb{E}_{t}\left[\int_{t}^{T_{D} \wedge T^{d}} \frac{B_{t}^{z}}{B_{s}^{z}} \frac{\partial V}{\partial X} \sigma d Z_{s}\right]=0 ; \\
\mathbb{E}_{t}\left[\int_{t}^{T_{D} \wedge T^{d}} \frac{B_{t}^{z}}{B_{s}^{z}}\left(\frac{1}{2} \sigma^{2} \frac{\partial^{2} V}{\partial X^{2}}+g \frac{\partial V}{\partial X}+\frac{\partial V}{\partial t}-r^{z} V\right) d s\right] \\
=-\mathbb{E}_{t}\left[\int_{t}^{T_{D} \wedge T^{d}} \frac{B_{t}^{z}}{B_{s}^{z}}\left(X_{t}\left(1-\tau_{t}^{c}\right)+\tau_{t}^{*} R_{t}\right) d s\right],
\end{gathered}
$$

from equation (3.4), and

$$
\begin{aligned}
\mathbb{E}_{t}\left[Y_{T_{D} \wedge T^{d}}\right]=\mathbb{E}_{t}\left[\chi_{\left\{\forall s \in\left[t, T^{d}\right], X_{s}>x_{D}\right\}} \frac{B_{t}^{z}}{B_{T^{d}}^{z}} V\left(T^{d}, X_{T^{d}}\right)\right] \\
+\mathbb{E}_{t}\left[\chi_{\left\{\exists s \in\left[t, T^{d}\right], X_{s}=x_{D}\right\}} \frac{B_{t}^{z}}{B_{T_{D}}^{z}} V\left(T_{D}, X_{T_{D}}\right)\right] .
\end{aligned}
$$

Hence, from equation (A.11) and the boundary conditions of the problem, we have

$$
\begin{aligned}
V(t, x)=\mathbb{E}_{t} & {\left[X_{\left\{\forall s \in\left[t, T^{d}\right], X_{s}>x_{D}\right\}} \frac{B_{t}^{z}}{B_{T^{d}}^{z}} U\left(T^{d}, X_{T^{d}}\right)\right] } \\
& +(1-\alpha) \mathbb{E}_{t}\left[\chi_{\left\{\exists s \in\left[t, T^{d}\right], X_{s}=x_{D}\right\}} \frac{B_{t}^{z}}{B_{T_{D}}^{z}} U\left(T_{D}, X_{T_{D}}\right)\right] \\
& +\mathbb{E}_{t}\left[\int_{t}^{T_{D} \wedge T^{d}} \frac{B_{t}^{z}}{B_{s}^{z}} X_{t}\left(1-\tau_{t}^{c}\right) d s\right]+\mathbb{E}_{t}\left[\int_{t}^{T_{D} \wedge T^{d}} \frac{B_{t}^{z}}{B_{s}^{z}} \tau_{t}^{*} R_{t} d s\right]
\end{aligned}
$$

that is, after few manipulations, equation (3.14). 


\section{Proof of Proposition 7}

To derive the valuation pde (3.15) for $D$, we follow the same argument we used in the proof of Proposition 5 and create a portfolio whose return replicates the return of the bond.

The return of the bond is, by Itô's Lemma

$$
\begin{aligned}
\frac{d D+R d t}{D}\left(1-\tau^{b}\right)=\frac{1}{D}\left(\frac{1}{2} \sigma^{2} \frac{\partial^{2} D}{\partial X^{2}}+\hat{g} \frac{\partial D}{\partial X}+\right. & \left.\frac{\partial D}{\partial t}+R\right)\left(1-\tau^{b}\right) d t \\
& +\frac{1}{D} \frac{\partial D}{\partial X} \sigma\left(1-\tau^{b}\right) d Z_{t}
\end{aligned}
$$

A long position in a portfolio with price $W=n_{1} B^{f}+n_{2} S$, where $B^{f}$ is the value of the money market account and $S$, as of (A.7), is the price of a (twin) security/portfolio for $X$ have a rate of return as in equation (A.9). Putting

$$
\frac{n_{2} S}{W}=\frac{\partial D / \partial X}{D} \frac{\sigma}{\beta} \frac{\left(1-\tau^{b}\right)}{\left(1-\tau^{e}\right)}
$$

we obtain, after few manipulations and using the generalized Miller equilibrium relation (2.5),

$$
\frac{1}{2} \sigma^{2} \frac{\partial^{2} V}{\partial X^{2}}+\left(\hat{g}-\sigma \frac{\alpha+\delta / S-r^{z}}{\beta}\right) \frac{\partial V}{\partial X}+\frac{\partial V}{\partial t}+R=r^{f} V
$$

that is (3.15) when $g=\hat{g}-\lambda \sigma$ in (A.10).

The existence of the solution for this problem can be derived from Lamberton and Lapeyre (1996, Th. 5.1.9).

To verify (3.16), let

$$
Y_{s}=\frac{B_{t}^{f}}{B_{S}^{f}} D\left(s, X_{s}\right) .
$$

By Itô's Lemma, we have

$$
\begin{aligned}
Y_{T_{D} \wedge T^{d}}=D(t, x)+\int_{t}^{T_{D} \wedge T^{d}} \frac{B_{t}^{f}}{B_{S}^{f}}\left(\frac{1}{2} \sigma^{2} \frac{\partial^{2} D}{\partial X^{2}}\right. & \left.+g \frac{\partial D}{\partial X}+\frac{\partial D}{\partial t}-r^{f} D\right) d s \\
& +\int_{t}^{T_{D} \wedge T^{d}} \frac{B_{t}^{f}}{B_{s}^{f}} \frac{\partial D}{\partial X} \sigma d Z_{s} . \quad \text { A. }
\end{aligned}
$$

We take expectations of both sides of the above equation. We note the following facts:

$$
\mathbb{E}_{t}\left[\int_{t}^{T_{D} \wedge T^{d}} \frac{B_{t}^{f}}{B_{S}^{f}} \frac{\partial D}{\partial X} \sigma d Z_{s}\right]=0
$$


since $D$ satisfies the pde (3.15), then

$$
\begin{array}{r}
\mathbb{E}_{t}\left[\int_{t}^{T_{D} \wedge T^{d}} \frac{B_{t}^{f}}{B_{s}^{f}}\left(\frac{1}{2} \sigma^{2} \frac{\partial^{2} D}{\partial X^{2}}+g \frac{\partial D}{\partial X}+\frac{\partial D}{\partial t}-r^{f} D\right) d s\right] \\
=-\mathbb{E}_{t}\left[\int_{t}^{T_{D} \wedge T^{d}} \frac{B_{t}^{f}}{B_{S}^{f}} R_{s} d s\right] ; \\
\mathbb{E}_{t}\left[Y_{T_{D} \wedge T^{d}}\right]=\mathbb{E}_{t}\left[\chi_{\left\{\forall s \in\left[t, T^{d}\right], X_{s}>x_{D}\right\}} \frac{B_{t}^{f}}{\left.B_{T^{d}}^{f} D\left(T^{d}, X_{T^{d}}\right)\right]}\right. \\
+\mathbb{E}_{t}\left[X_{\left\{\exists s \in\left[t, T^{d}\right], X_{s}=x_{D}\right\}} \frac{B_{t}^{f}}{\left.B_{T_{D}}^{f} D\left(T_{D}, X_{T_{D}}\right)\right] .}\right.
\end{array}
$$

From the above equations, using the boundary conditions $D\left(T^{d}, X_{T^{d}}\right)=$ $P$ and $D\left(s, x_{D}\right)=(1-\alpha) U\left(s, x_{D}\right)$ for all $t \leq s \leq T^{d}$, with $X_{T_{D}}=x_{D}$, we have

$$
\begin{aligned}
& \mathbb{E}_{t}\left[X_{\left\{\forall s \in\left[t, T^{d}\right], X_{s}>x_{D}\right\}} \frac{B_{t}^{f}}{B_{T^{d}}^{f}} P\right] \\
&+\mathbb{E}_{t}\left[\chi_{\left\{\exists s \in\left[t, T^{d}\right], X_{s}=x_{D}\right\}} \frac{B_{t}^{f}}{B_{T_{D}}^{f}}(1-\alpha) U\left(T_{D}, x_{D}\right)\right] \\
&=D(t, x)-\mathbb{E}_{t}\left[\int_{t}^{T_{D} \wedge T^{d}} \frac{B_{t}^{f}}{B_{S}^{f}} R_{s} d s\right]
\end{aligned}
$$

that is, equation (3.16).

\section{Derivation of equation (3.17)}

Under the restrictive assumptions that: $\tau^{c}, \tau^{e}, \tau^{b}, r^{f}, r^{z}$ are constant; in (3.1) $g(X, t)=g X, \sigma(X, t)=\sigma X$, with $g$ and $\sigma$ constant; constant coupon payment, $R$, and principal, $P$, from (3.14)

$$
\begin{aligned}
V(t, x)= & x\left(1-\tau^{c}\right) \frac{1-e^{-\left(r^{z}-g\right)\left(T^{p}-t\right)}}{r^{z-g}} \\
& +\tau^{*} R \int_{t}^{T^{d}} e^{-r^{z}(s-t)}\left(1-H\left(s, x_{D}, x, t\right)\right) d s \\
& -\int_{t}^{T^{d}} e^{-r^{z}(s-t)} \alpha x_{D}\left(1-\tau^{c}\right) \frac{1-e^{-\left(r^{z}-g\right)\left(T^{p}-s\right)}}{r^{z}-g} h\left(s, x_{D}, x, t\right) d s
\end{aligned}
$$


where $h\left(s, x_{D}, x, t\right)$ is the density and $H\left(s, x_{D}, x, t\right)$ is the cumulative distribution function of the first hitting time $s$ to $x_{D}$ for a geometric Brownian motion, under the EMM, with starting point $X_{t}=x$.

Integrating by parts the second term in the right-hand-side of the above equation and after few manipulations we obtain

$$
\begin{gathered}
V(t, x)=U(t, x)+\frac{\tau^{*} R}{r^{z}}-\left(\frac{\tau^{*} R}{r^{z}}+\frac{\alpha x_{D}\left(1-\tau^{c}\right)}{r^{z}-g}\right) \int_{t}^{T^{d}} e^{-r^{z}(s-t)} h\left(s, x_{D}, x, t\right) d s \\
+\frac{\alpha x_{D}\left(1-\tau^{c}\right)}{r^{z}-g} e^{\left(r^{z}-g\right)\left(T^{p}-t\right)} \int_{t}^{T^{d}} e^{-g(s-t)} h\left(s, x_{D}, x, t\right) d s \\
-\frac{\tau^{*} R}{r^{z}} e^{-r^{z}\left(T^{d}-t\right)}\left(1-H\left(s, x_{D}, x, t\right)\right)
\end{gathered}
$$

where $U$ is defined in (3.9). We denote

$$
G\left(T^{d}, x_{D}, x, t, r\right)=\int_{t}^{T^{d}} e^{-r(s-t)} h\left(s, x_{D}, x, t\right) d s .
$$

$G$ is explicitly computed in equation (3.19) (details in Reiner and Rubinstein (1991)) and $H$ from equation (3.18) can be found in Harrison (1985, pp. 11-14).

\section{Derivation of equation (3.21)}

Under the same restrictive assumptions of equation (3.17), from (3.16) we have

$$
\begin{gathered}
D(t, x)=R \int_{t}^{T^{d}} e^{-r^{f}(s-t)}\left(1-H\left(s, x_{D}, x, t\right)\right) d s \\
\quad+e^{-r^{f}\left(T^{d}-t\right)} P\left(1-H\left(T^{d}, x_{D}, x, t\right)\right) \\
+\frac{(1-\alpha) x_{D}\left(1-\tau^{c}\right)}{r^{z}-g} \int_{t}^{T^{d}} e^{-r^{f}(s-t)}\left(1-e^{-\left(r^{z}-g\right)\left(T^{p}-s\right)}\right) h\left(s, x_{D}, x, t\right) d s .
\end{gathered}
$$


Integrating by parts the first term in the right-hand-side of the equation above and after few manipulations, we obtain

$$
\begin{aligned}
D(t, x)= & \frac{R}{r^{f}}-\frac{R}{r^{f}} \int_{t}^{T^{d}} e^{-r^{f}(s-t)} h\left(s, x_{D}, x, t\right) d s \\
& +e^{-r^{f}\left(T^{d}-t\right)}\left(P-\frac{R}{r^{f}}\right)\left(1-H\left(T^{d}, x_{D}, x, t\right)\right) \\
+ & \frac{(1-\alpha) x_{D}\left(1-\tau^{c}\right)}{r^{z}-g}\left(\int_{t}^{T^{d}} e^{-r^{f}(s-t)} h\left(s, x_{D}, x, t\right) d s\right. \\
& \left.+e^{-\left(r^{z}-g\right)\left(T^{p}-t\right)} \int_{t}^{T^{d}} e^{-\left(r^{f}-r^{z}+g\right)(s-t)} h\left(s, x_{D}, x, t\right) d s\right) .
\end{aligned}
$$

Using definition (A.13) and from the generalized Miller equilibrium relation in (2.6), we have (3.21).

\section{Proof of Proposition 8}

The proof that $F$ satisfies equation (4.2) is the same as for the proof of Proposition 5. The solution in (4.3) is derived using standard results (see Duffie (2001, pp. 182-186)).

\section{Proof of Proposition 9}

The value of the European option with maturity $T^{o}$ and payoff $\Pi\left(t, X_{t}\right)$ from (4.1) is

$$
f(t, X)=e^{-\left(r_{z}-g\right)\left(T^{o}-t\right)} \mathcal{N}\left(m_{1}\right) V(t, x)-e^{r_{z}\left(T^{o}-t\right)} \mathcal{N}\left(m_{2}\right) I
$$

with

$$
m_{1}(x)=\frac{\log \frac{V(t, x)}{I}+\left(g+\frac{\sigma^{2}}{2}\right)\left(T^{o}-t\right)}{\sigma \sqrt{T^{o}-t}}, \quad m_{2}=m_{1}-\sigma \sqrt{T^{o}-t} .
$$


where $V(t, x)=x K(t)$ from equations (3.9), (3.10) and (3.11) in the default-free case, with

$$
\begin{aligned}
& K(t)=\left(1-\tau^{c}\right) \frac{1-e^{-\left(r^{z}-g\right)\left(T^{p}-t\right)}}{r^{z}-g} \\
& +\left(1-\tau^{c}\right) r^{f} \tau^{*} L \frac{\left(1-e^{-\left(r^{z}-g\right)\left(T^{d}-t\right)}\right)}{\left(r^{z}-g\right)\left(r^{z}-r^{f} \tau^{*} L-g\right)} \\
& \quad+\left(1-\tau^{c}\right) e^{-\left(r^{z}-g\right)\left(T^{d}-t\right)} \frac{\left(1-e^{\left(r^{f} T^{*} L\right)\left(T^{d}-t\right)}\right)}{\left(r^{z}-r^{f} T^{*} L-g\right)},
\end{aligned}
$$

and $V(t, x)$ as defined in equation (3.17) in the defaultable case.

The early-exercise premium of the real option to delay investment, denoted $E(t, x)=F(t, x)-f(t, x)$, satisfies equation

$$
\frac{1}{2} \sigma^{2} X_{t}^{2} \frac{\partial^{2} E}{\partial X^{2}}+g X_{t} \frac{\partial E}{\partial X}+\frac{\partial E}{\partial t}=r^{z} E
$$

$E$ is approximated by

$$
\widetilde{E}(t, x)=\varphi x^{\eta} h\left(T^{o}-t\right),
$$

where $h(s)=1-e^{-r_{z} s}$ and $\varphi$ and $\eta$ are parameters to be determined. By replacing $\widetilde{E}$ in equation (A.14), we get

$$
\eta(\eta-1)+2 \frac{g}{\sigma} \eta-2 \frac{r^{z}}{\sigma^{2} h\left(T^{o}-t\right)}=0 .
$$

$\eta$ is known and is the positive root of the above equation:

$$
\eta\left(r^{z}\right)=\eta=\frac{1}{2}-\frac{g}{\sigma^{2}}+\sqrt{\left(\frac{1}{2}-\frac{g}{\sigma^{2}}\right)^{2}+2 \frac{r_{z}}{\sigma^{2} h\left(T^{o}-t\right)}}>1 .
$$

At the critical level for the cash flow rate, denoted $x_{t}^{*}$, the value of the real options, $F$, must satisfies the value-matching and smooth-pasting conditions. Hence, for the approximation $\widetilde{F}(t, x)=f(t, x)+\widetilde{E}(t, x)$ the following conditions hold:

$$
\begin{gathered}
f\left(t, x_{t}^{*}\right)+\varphi\left(x_{t}^{*}\right)^{\eta} h\left(T^{o}-t\right)=V\left(t, x_{t}^{*}\right)-I \\
\left.\frac{\partial f(t, x)}{\partial X}\right|_{x=x_{t}^{*}}+\varphi \eta\left(x_{t}^{*}\right)^{\eta-1} h\left(T^{o}-t\right)=\left.\frac{\partial V(t, x)}{\partial X}\right|_{x=x_{t}^{*}}
\end{gathered}
$$


We solve the above system for $\varphi$ and $x_{t}^{*}$. In the defaultable case, we have to rely on a numerical solution for both $\varphi$ and $x_{t}^{*}$. Existence and uniqueness of solution is given by the strict monotonicity of $V(t, x)$ with respect to $x$, for $x>x_{D}$.

On the other hand, in the default-free case, equation (A.17) can be simplified as follows

$$
e^{-\left(r_{z}-g\right)\left(T^{o}-t\right)} \mathcal{N}\left(m_{1}\left(x_{t}^{*}\right)\right) K(t)+\varphi \eta\left(x_{t}^{*}\right)^{\eta-1} h\left(T^{o}-t\right)=K(t)
$$

From (A.18) we solve for $\varphi$ :

$$
\varphi=\frac{K(t)\left(1-e^{-\left(r^{z}-g\right)\left(T^{o}-t\right)} \mathcal{N}\left(m_{1}\left(x_{t}^{*}\right)\right)\right)}{\left(x^{*}\right)^{\eta-1} \eta h\left(T^{o}-t\right)} .
$$

By replacing this in (A.16) we solve equation

$$
f\left(t, x_{t}^{*}\right)+\left(1-e^{-\left(r^{z}-g\right)\left(T^{o}-t\right)} \mathcal{N}\left(m_{1}\left(x_{t}^{*}\right)\right)\right) \frac{K(t) x_{t}^{*}}{\eta}=V\left(t, x_{t}^{*}\right)-I
$$

for $x_{t}^{*}$ (using a numerical method).

This completely determines the approximation $\widetilde{F}$ as in equation (5.1). 
Table 1: Option to delay: base case parameters

\begin{tabular}{clll}
\hline$r_{z}$ & CE return for stocks & 0.07 & \\
$\tau^{c}$ & corporate tax rate & 0.4 & \\
$\tau^{e}$ & tax rate for equity flows & 0.1 & \\
$\tau^{b}$ & tax rate for bond flows & 0.2 & \\
$x$ & current EBIT rate & 1 & \\
$g$ & risk-neutral growth rate of $X_{t}$ & 0.02 & \\
$\sigma$ & volatility of $X_{t}$ & 0.35 & \\
$\Phi$ & risk-premium rate for $X_{t}$ & 0.05 & \\
$T^{p}$ & duration of the project & 10 & (years) \\
$T^{d}$ & duration of debt & 10 & (years) \\
$T^{o}$ & expiry of the option to delay & 1 & (years) \\
$\alpha$ & bankruptcy (proportional) costs & 0.25 & \\
$L$ & leverage (in M-E) & 0.57 & \\
$R$ & total coupon payment (in M-M) & 0.3 & $(\$)$ \\
$P$ & face value of bond (in M-M) & 3.8 & $(\$)$ \\
$x_{D}$ & exogenous default threshold (in M-M) & 0.3 & \\
$I$ & capital expenditure & 5 & $(\$)$ \\
\hline
\end{tabular}

For these parameters, from (2.1), $\tau^{m}=0.111, \tau^{*}=\tau^{c}-\tau^{m}=0.289$, from (2.6), $r^{f}=0.079$, and, from equation (3.7), $\rho=0.057$.

The APV of the project in the default-free case is, from equation (3.12), $V=5.014$ and the market value of debt is $D=L \cdot V \approx 2.858$.

The APV of the project in the defaultable case is, from equation (3.17), $V=5.197$ and the market value of debt is, from equation (3.21), $D=2.960$. Note that the face value is set so that $P \approx R / r^{f}$. The initial leverage in the defaultable case is $L=D / V=0.569 \approx 0.57$, that is the same for the the default-free case. 

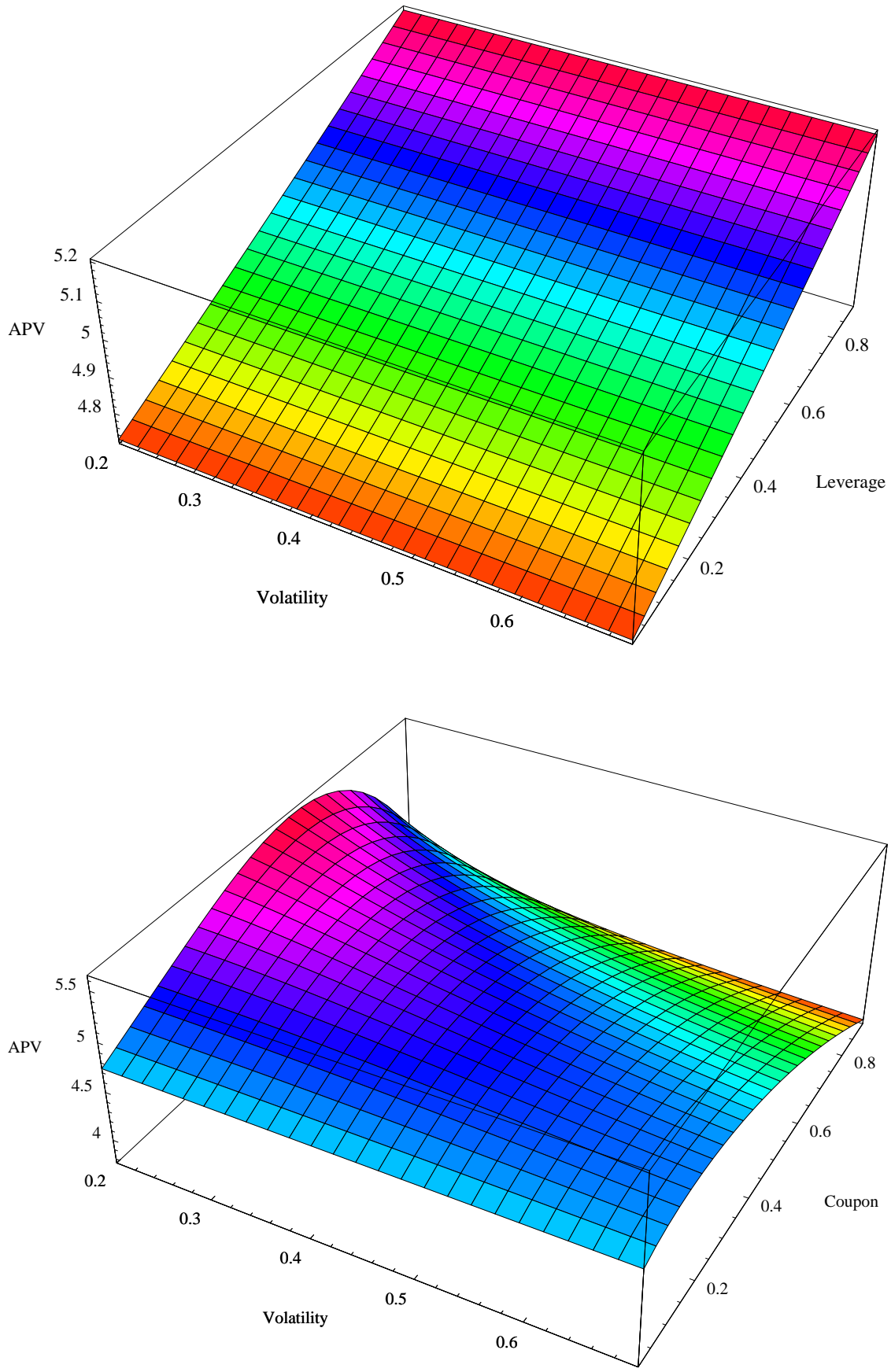

Figure 1: APV of the project. Value of the project, $V$, including the debt tax shield, vs volatility of EBIT process, $\sigma$, and debt level (represented by the coupon payment, $R$, in the defaultable case and by leverage, $L$, in the default-free case). Default-free case is above and defaultable case is below. The other parameters are from Table 1. 

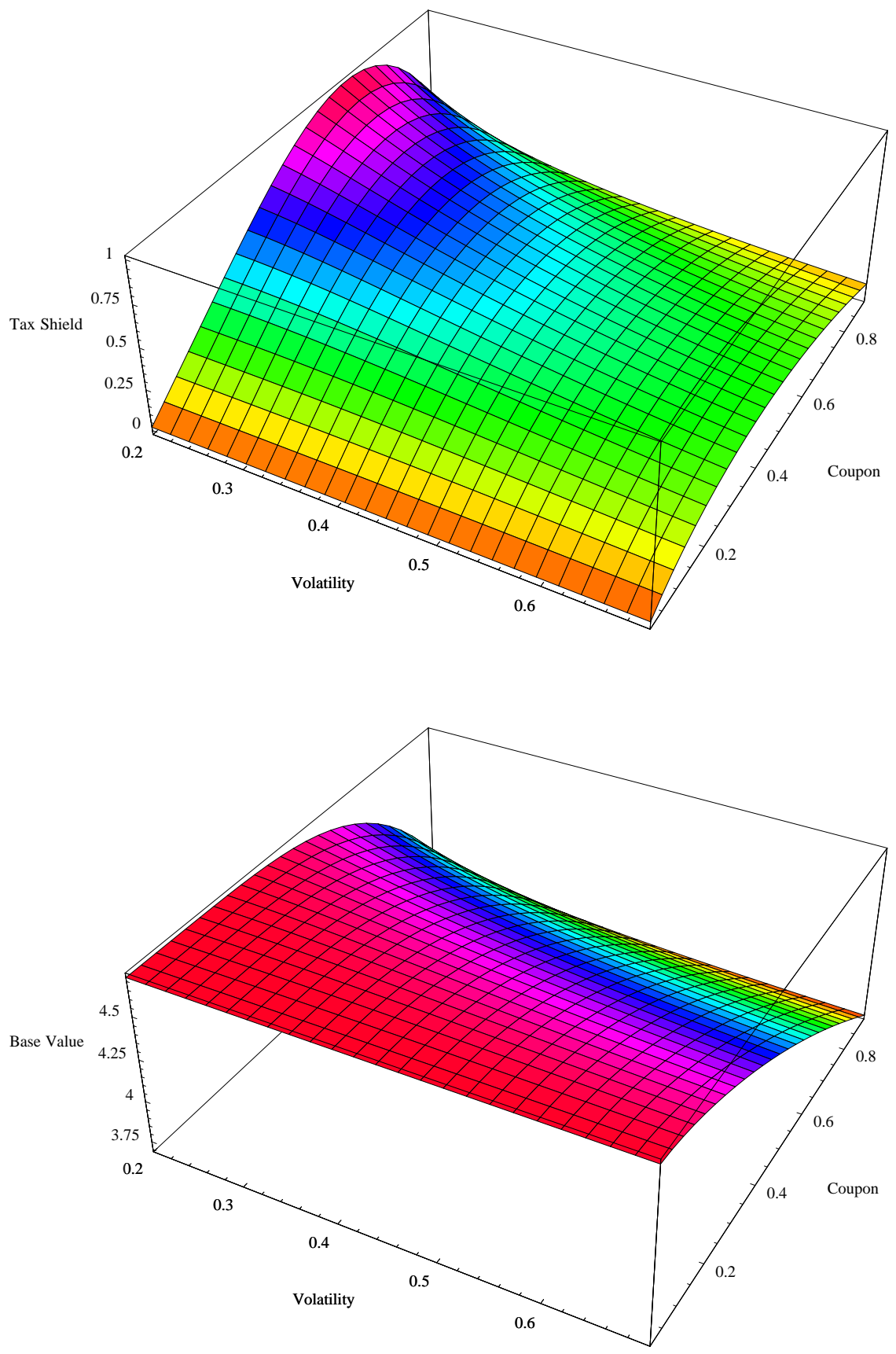

Figure 2: Tax Shield and Base Value - defaultable case. Value of the tax shield, $T S$, and base value (defined as the APV net of the tax shield), vs volatility of EBIT process, $\sigma$, and debt level (represented by the coupon payment, $R$ ). The other parameters are from Table 1. 

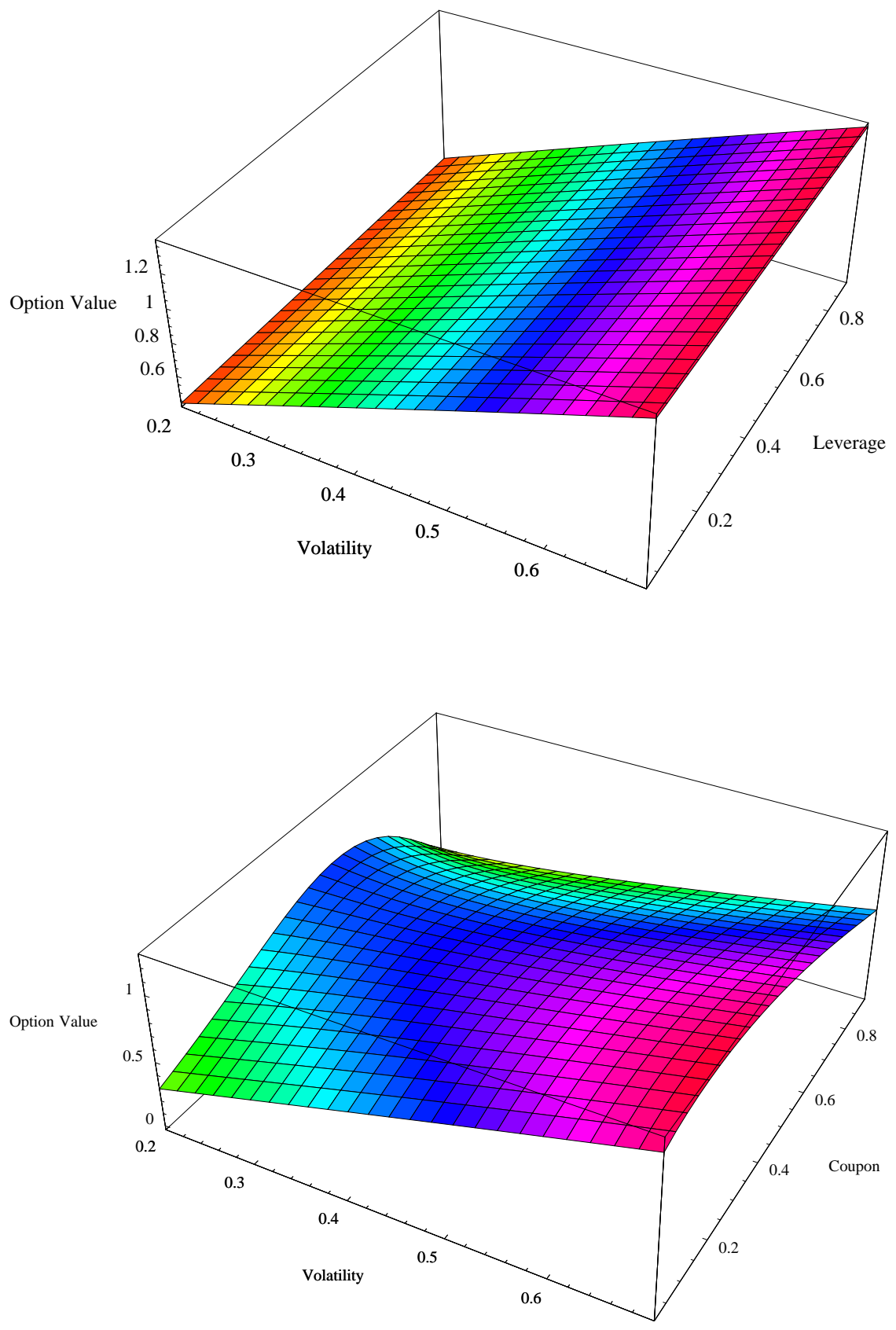

Figure 3: Option to invest. Value of the option to invest, $\widetilde{F}$, vs volatility of EBIT process, $\sigma$, and debt level (represented by the coupon payment, $R$, in the defaultable case and by leverage, $L$, in the default-free case). Defaultfree case is above and defaultable case is below. The other parameters are from Table 1. 

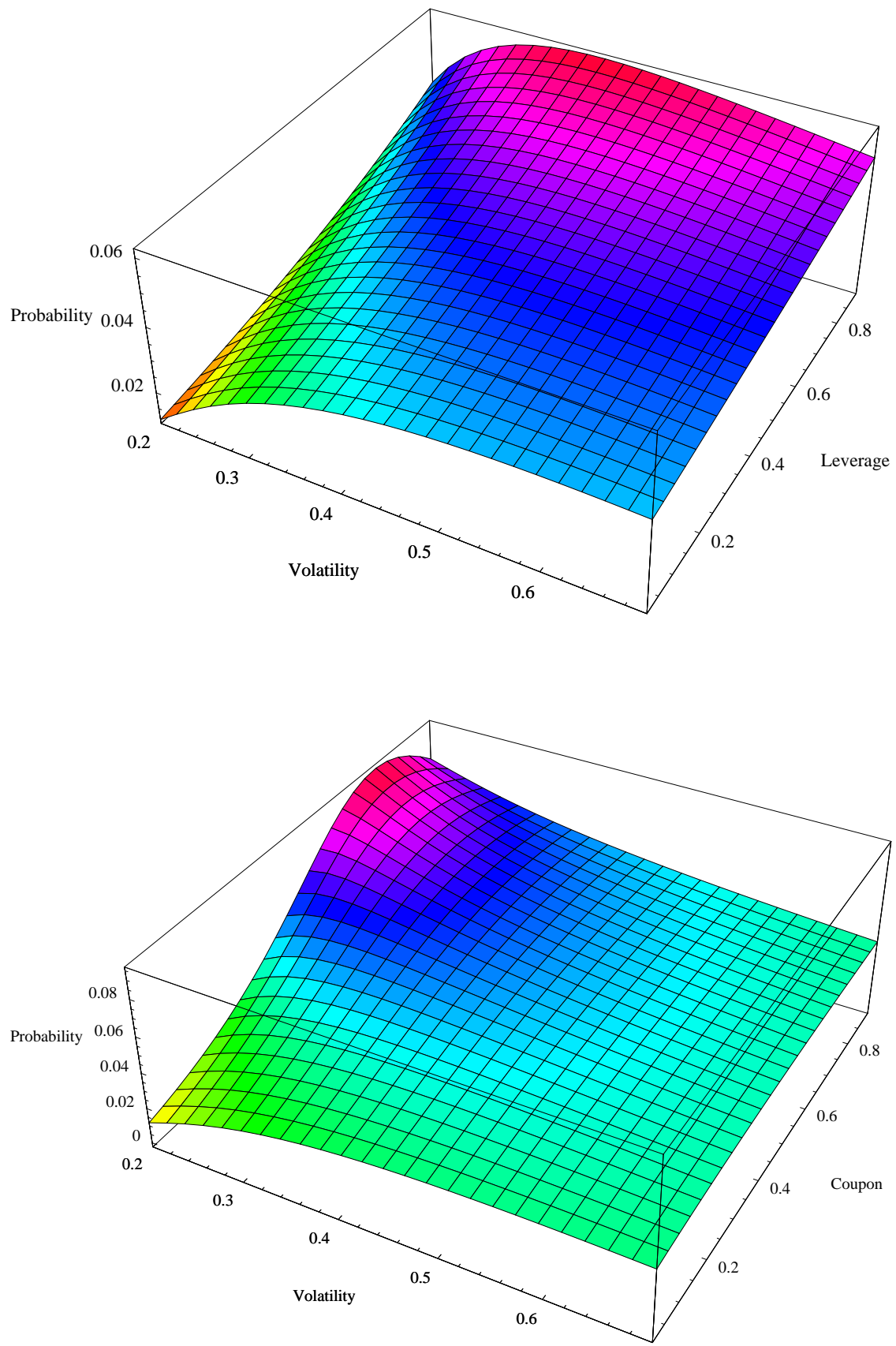

Figure 4: Probability of investing. Probability of exercising the option to invest, $H$, vs volatility of EBIT process, $\sigma$, and debt level (represented by the coupon payment, $R$, in the defaultable case and by leverage, $L$, in the default-free case). Default-free case is above and defaultable case is below. The other parameters are from Table 1. 